Martin Mohr

\title{
An welcher Stelle lag die archaisch-klassische Siedlung von Ephesos? Neue Überlegungen zur archäologischen und literarischen Evidenz ${ }^{1}$
}

\begin{abstract}
An welcher Stelle lag die archaisch-klassische Siedlung von Ephesos? Diese Frage mag auf den ersten Blick unberechtigt erscheinen, wird doch die sog. griechische Stadt ${ }^{2}$ in der Forschung einhellig am Ayasoluk oder in der Ebene beim Artemision lokalisiert (Abb. 1) ${ }^{3}$. Ihre Entstehung wird im Zusammenhang mit der militärischen Intervention des Königs Kroisos nach 560 v. Chr. gesehen, welche einen erbitterten Wettstreit um die zentrale Macht zur Folge hatte. Erst eine politische Neuordnung der ephesischen Polisgemeinschaft, die möglicherweise mit einem Synoikismos der umliegenden Siedlungen verbunden war, schuf die nötigen Voraussetzungen für eine Stabilisierung der Polis. Für die Topographie der Vorgängersiedlung im Bereich
\end{abstract}

\footnotetext{
${ }^{1}$ Die folgenden Ausführungen bauen auf Forschungen auf, die der Verfasser im Rahmen seiner Lizentiatsarbeit über sog. Heilige Straßen durchgeführt hat, welche im Mai 2004 von der Philosophischen Fakultät der Universität Zürich angenommen wurde. Für die Bereitschaft, sich mit dem Manuskript kritisch auseinanderzusetzen, bin ich Prof. em. Dr. Hans Peter Isler und Prof. Dr. Erich Kistler zu großem Dank verpflichtet. Mein Dank gilt insbesondere auch Mag. Anna Bischoff, Julie Freudiger, Dr. sc. techn. Christian Marti, Robert Mohr und Dr. Christian Utzinger, die mit Rat und konstruktiver Kritik meine Arbeit begleitet haben. - Abkürzungen und Zitate folgen den Richtlinien des Österreichischen Archäologischen Instituts <http:// www.oeai.at/publik/autoren.html>, darüber hinaus werden folgende verwendet:

Karwiese $1995 \quad$ St. Karwiese, Groß ist die Artemis von Ephesos. Die Geschichte einer der großen Städte der Antike (Wien 1995).

Knibbe 1998 D. Knibbe, Ephesus. Geschichte einer bedeutenden antiken Stadt und Portrait einer modernen Großgrabung im 102. Jahr der Wiederkehr des Beginnes österreichischer Forschungen (1895-1997) (Frankfurt am Main 1998).

Kraft - Kayan - Brückner 1999 J. C. Kraft - İ. Kayan - H. Brückner, The Interpretation of Ancient Environments and their Resultant Paleogeographies in the Environs of the Feigengarten and Artemision Excavations at Ephesus, in: P. Scherrer - H. Taeuber - H. Thür (Hrsg.), Steine und Wege. Festschrift Dieter Knibbe, SoSchrÖAI 32 (Wien 1999) 91-100.

Kraft - Kayan - Brückner 2001 J. C. Kraft - İ. Kayan - H. Brückner, The Geological and Paleogeographical Environs of the Artemision, in: U. Muss (Hrsg.), Der Kosmos der Artemis von Ephesos, SoSchrÖAI 37 (Wien 2001) 123-133.

Kraft - Kayan - Brückner - Ripp $2000 \quad$ J. C. Kraft - İ. Kayan - H. Brückner - G. Ripp (Rap), A Geologic Analysis of Ancient Landscapes and the Harbors of Ephesus and the Artemision in Anatolia, ÖJh 69, 2000, $175-233$.

Radt 2005 St. Radt (Hrsg.), Strabons Geographika IV. Buch XIV-XVII: Text und Übersetzung (Göttingen 2005).

Scherrer 1999 P. Scherrer, Bemerkungen zur Siedlungsgeschichte von Ephesos vor Lysimachos, in: H. Friesinger - F. Krinzinger (Hrsg.), 100 Jahre Österreichische Forschungen in Ephesos. Akten des Symposions Wien 1995, AForsch 1 = DenkschrWien 260 (Wien 1999) 379-387.

Scherrer 2001 P. Scherrer, The Historical Topography of Ephesos, in: D. Parrish (Hrsg.), Urbanism in Western Asia Minor. New Studies on Aphrodisias, Ephesos, Hierapolis, Pergamon, Perge and Xanthos, JRA Suppl. 45 (Portsmouth, Rhode Island 2001) 57-96.

Scherrer - Trinkl $2006 \quad$ P. Scherrer - E. Trinkl, Die Tetragonos Agora in Ephesos, FiE 13, 2 (Wien 2006).

${ }^{2}$ Die Bezeichnung für die archaisch-klassische Siedlung von Ephesos, wie sie seit der Machtübernahme des Königs Kroisos bis zur Neugründung des Lysimachos nach 300 v. Chr. bestand, ist wenig glücklich, einmal in die Fachliteratur eingeführt jedoch unverzichtbar.

${ }^{3}$ U. Muss, Die Bauplastik des archaischen Artemisions von Ephesos, SoSchrÖAI 25 (Wien 1994) 28; Karwiese 1995, 33 f.; F. Hueber, Ephesos. Gebaute Geschichte, AW Sonderh. (Mainz 1997) 34-38; Knibbe 1998, 81; Kraft - Kayan - Brückner
} 


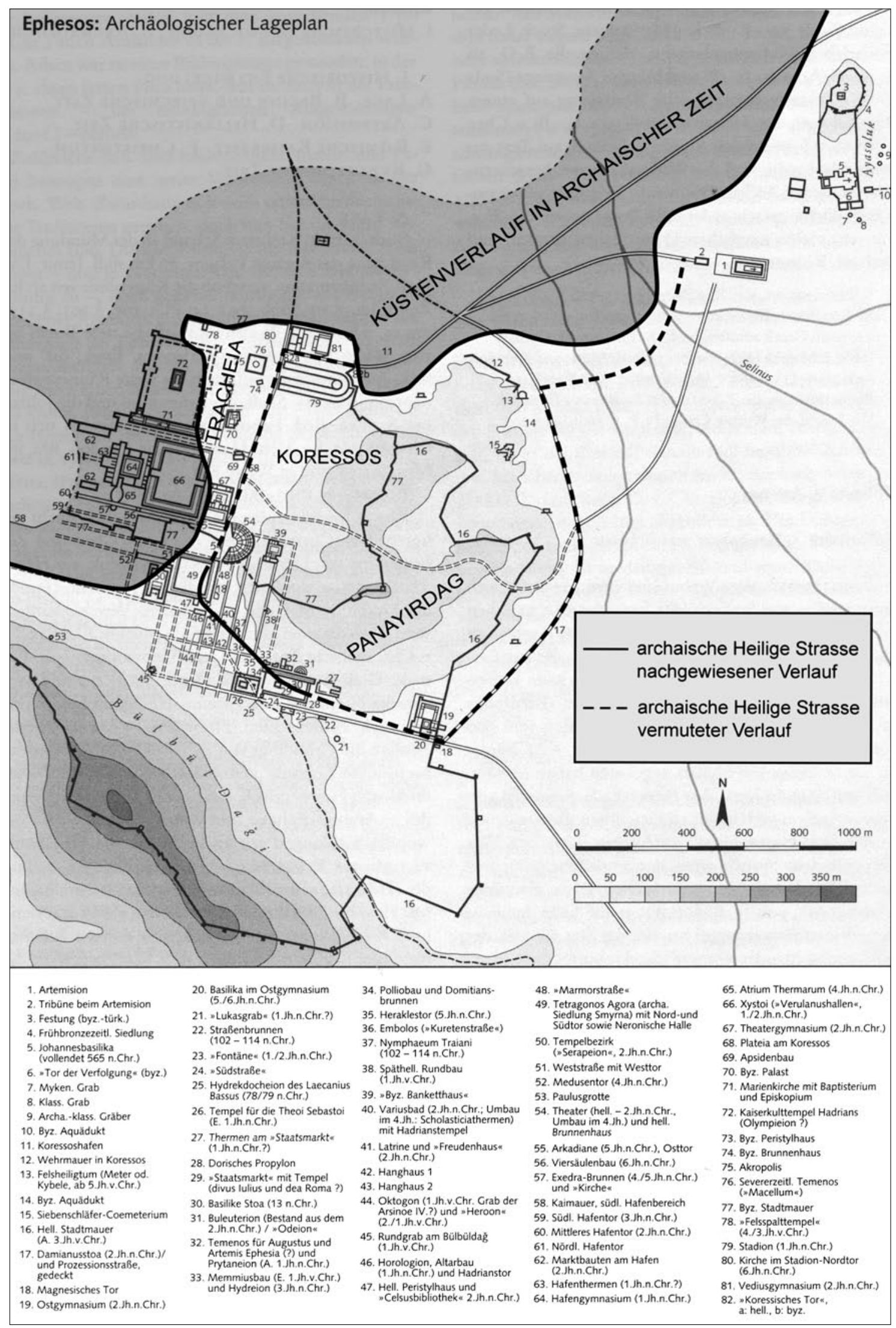

1 Archäologischer Lageplan und historische Topographie von Ephesos 
des römischen Stadions (Abb. 1 Nr. 79) dürfte dies tatsächlich nicht ohne Auswirkungen geblieben sein: Bezeichnenderweise wurde zu dieser Zeit eine archäologisch bisher vom Ostende des >Staatsmarktes` bis in den östlichen Teil der Tetragonos Agora nachgewiesene Straße angelegt, welche bis in das ausgehende 4. Jahrhundert v. Chr. als Gräberstraße diente und deren Verlauf selbst bei der Planung und Ausführung des hellenistisch-römischen Stadtplanes unangetastet blieb (Abb. 1).

Damit erinnert dieser Straßenabschnitt unmittelbar an die im selben zeitlichen und geographischen Horizont angelegten sakralen Straßenachsen ${ }^{4}-$ sog. Heilige Straßen ${ }^{5}-$ auf Samos sowie zwischen Milet und Didyma, welche die Poleis mit dem jeweils wichtigsten extraurbanen Heiligtum verbanden und außerhalb des Stadtgebietes eine Nekropole erschlossen ${ }^{6}$. Vor dem Hintergrund der möglichen Existenz einer Heiligen Straße in Ephesos, welche die Polis seit der Machtübernahme des Kroisos mit dem Artemision verband, gewinnt nun die Frage nach der Lage der archaisch-klassischen Siedlung erneut an Aktualität, da sie sich nicht mit der gängigen Meinung zur Topographie der griechischen Stadt verbinden lässt. Die eingehende Beschäftigung mit der >Heiligen Straße von Ephesos` zog daher unweigerlich auch eine kritische Revision der archäologischen und literarischen Quellen zur Lage der archaisch-klassischen Siedlung nach sich. Diese sich daraus ergebenden neuen Ergebnisse und Fragestellungen sollen mit diesem Beitrag zur Diskussion vorgelegt werden.

1999, 96 Abb. 3; Scherrer 1999, 382; Kraft - Kayan - Brückner - Ripp 2000, 185 f. Abb. 6. 10; Kraft - Kayan - Brückner 2001, 123 Taf. 5. 6; Scherrer 2001, 61; Scherrer - Trink1 2006, 59. 261 Plan 3; St. Groh, Neue Forschungen zur Stadtplanung in Ephesos, ÖJh 75, 2006, 54. Von besonderem Interesse wird diesbezüglich die in Druck befindliche Publikation von M. Kerschner - I. Kowalleck - M. Steskal, Archäologische Forschungen zur Siedlungsgeschichte von Ephesos in geometrischer, archaischer und klassischer Zeit. Grabungsbefunde und Keramikbefunde aus dem Bereich von Koressos, ErghÖJh 9 (Wien 2008), sein. Dezidiert kritisch zu einer Lokalisierung der griechischen Stadt am Ayasoluk bzw. in der Ebene südlich des Artemisions äußerte sich bisher einzig Ö. Özyiğit, Spätarchaische Funde im Museum von Ephesos und die Lage von Alt-Ephesos, IstMitt 38, 1988, 95 f. Ähnlich jetzt auch L. Rubinstein, Ephesos, in: M. H. Hansen - T. H. Nielsen (Hrsg.), An Inventory of Archaic and Classical Poleis. Copenhagen Polis Centre for the Danish National Research Foundation (Oxford 2004$) 1072$.

${ }^{4}$ Zum Begriff und den sakralen Achsen im Allgemeinen vgl. T. Hölscher, Öffentliche Räume in frühen griechischen Städten (Heidelberg 1998) 74-83.

5 Die Bezeichnung >Heilige Straßeく lässt sich durch epigraphische Funde und die literarische Überlieferung mehrfach belegen und scheint in der Antike allgemein für Straßen angewandt worden zu sein, welche eine Polis mit einem wichtigen extra- oder intraurbanen Heiligtum verbanden. Hdt. 6, 34 bezeichnet die Straße zwischen Athen und Delphi ebenso als Heilige Straße, wie auch die Athener gemäß Paus. 1, 36, 3 die Straße, welche Athen und Eleusis verband, [...] ódòv í@óv [...] nannten. Diese Bezeichnung ist auch für die Straße zwischen Milet und Didyma überliefert (vgl. R. Harder [Hrsg.], Th. Wiegand, Didyma II. Die Inschriften von Albert Harder [Berlin 1958] 49 f. Nr. 40 Z. 11-12) und hielt sich bis in römische Zeit (vgl. A. v. Gerkan, Die Stadtmauern. Mit einem epigraphischen Beitrag von A. Rehm, Milet 2, 3 [Berlin 1935] 133 f. Nr. 402 Z. 4-5). Ursprünglich wurde diese Straße ódò $\pi \lambda \alpha \tau \varepsilon \tau ̃ \alpha$ genannt (vgl. G. Kawerau - A. Rehm, Das Delphinion in Milet, Milet 1, 3 [Berlin 1914] 277-279 Nr. 133 Z. 27). Daneben existierten aber auch spezifischere Bezeichnungen, welche sich direkt auf das Heiligtum oder die auf der Heiligen Straße stattfindenden Prozessionen bezogen. Als Beispiele seien hier die Straße zwischen Sparta und Amyklai, welche nach Athen. 4, 173-174 Hyakinthos-Straße genannt wurde, die Panathenäen-Straße in Athen und die

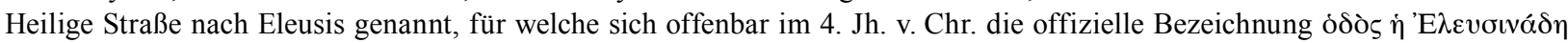
eingebürgert hat. Vgl. dazu IG I² 881; IG II ${ }^{2}$ 2624. Daher wird der zwischen dem Ostende des Staatsmarktes und der Tetragonos Agora nachgewiesene Straßenabschnitt in der Folge als Heilige Straße bezeichnet. Zur römischen `Via Sacra Ephesiaca<, welche den Verlauf der archaischen Gräberstraße nachweislich aufnahm, vgl. D. Knibbe - G. Langmann, Via Sacra Ephesiaca I, BerMatÖAI 3 (Wien 1995); D. Knibbe - H. Thür, Via Sacra Ephesiaca II, BerMatÖAI 6 (Wien 1995); D. Knibbe, Via Sacra Ephesiaca, in: H. Friesinger - F. Krinzinger, 100 Jahre Österreichische Forschungen in Ephesos. Akten des Symposions Wien 1995, AForsch 1 = DenkschrWien 260 (Wien 1999) 449-454; H. Thür, ,Via Sacra Ephesiaca<. Vor der Stadt und in der Stadt, in: P. Scherrer - H. Taeuber - H. Thür, Steine und Wege. Festschrift Dieter Knibbe, SoSchrÖAI 32 (Wien 1999) 163-172. Zum Verlauf der Prozessionsstraße in hellenistisch-römischer Zeit vgl. jetzt insbesondere Groh (Anm. 3) 71 f. Abb. 3. 10. 11. 19. 20.

${ }^{6}$ Zur Heiligen Straße zwischen Samos und dem Heraion vgl. zuletzt H. J. Kienast, Wege und Tore im Heraion von Samos, in: J. Cobet u. a. (Hrsg.), Frühes Ionien. Eine Bestandsaufnahme, Panionion-Symposion. Güzelçaml1, 26. September - 1. Oktober 1999, MilForsch 5 (Mainz 2007) 201-29; H. J. Kienast, Topography and Architecture of the Archaic Heraion at Samos, in: M. Stamatopoulou - M. Yeroulanou (Hrsg.), Excavating Classical Culture: Recent Archaeological Discoveries in Greece, Studies in Classical Archaeology I (Oxford 2002) 317-325; H. Kyrieleis - H. J. Kienast - H.-J. Weisshaar, Die Grabungen im Heraion von Samos 1980/81, AA 1985, 365-450. Zur Heiligen Straße zwischen Milet und Didyma vgl. jetzt A. Herda, Der Apollon-Delphinios-Kult in Milet und die Neujahrsprozession nach Didyma. Ein neuer Kommentar zur sog. Molpoi-Satzung (Milet 1, 3 Nr. 133), MilForsch 4 (Mainz 2006); P. Schneider, Zur Topographie der Heiligen Straße von Milet nach Didyma, AA 1987, 101-129. Eine umfassende Studie über Heilige Straßen wird derzeit vom Verfasser im Rahmen eines durch ein Stipendium aus dem Forschungskredit der Universität Zürich geförderten Dissertationsprojektes vorbereitet. 


\section{Historische Ausgangslage}

Als die Siedlung Ephesos unter der Herrschaft des Tyrannen Pindaros (ca. 560 v. Chr.) stand, begann König Kroisos (ca. 560-547 v. Chr.) die Herrschaft des Lyderreichs auszudehnen? ${ }^{7}$ Kurz nach seiner Machtübernahme forderte er die Städte an der Westküste Kleinasiens und die dort regierenden Tyrannen auf, sich ihm zu unterwerfen ${ }^{8}$. Als sich die Tyrannen weigerten, der Aufforderung nachzukommen, ergriff Kroisos die Initiative und zog zuerst, d. h. wohl kurz nach 560 v. Chr., gegen seinen Neffen Pindaros und belagerte die Akropolis der Siedlung9. Die sog. altionische Siedlung ${ }^{10}$ wird - wie dies bereits J. Keil vorgeschlagen hat ${ }^{11}-$ in der Forschung zumeist in der Umgebung des römischen Stadions lokalisiert ${ }^{12}$. Eine Nutzung dieses Bereichs als Siedlungsgebiet ist anhand des archäologischen Befundes bisher jedoch nicht vor der zweiten Hälfte des 8. Jahrhunderts v. Chr. nachzuweisen ${ }^{13}$. Mit guten Gründen tritt M. Kerschner deshalb für eine Lokalisierung der altionischen Siedlung am Ayasoluk ein, wo aufgrund der Keramikfunde von einer entsprechenden früheisenzeitlichen Siedlung auszugehen ist ${ }^{14}$. Aufgrund der literarischen Überlieferung kann sich die Siedlung Ephesos zu Zeiten des Kroisos hingegen nur im Bereich des römischen Stadions befunden haben ${ }^{15}$ : Der `Koressos-Hafen befand sich nordöstlich des späteren Stadions (Abb. 1 Nr. 11), während die Akropolis wohl auf der nördlichen Hügelkuppe des Panayırdağ, südöstlich des Stadions, zu lokalisieren ist (Abb. 1) ${ }^{16}$. Die Siedlung lag vermutlich an den Hängen südlich und südwestlich des Koressos-Hafens (Umgebung des römischen Stadions) und auf einem vom Panayırdağ ehemals weit ins Meer vorspringenden Ausläufer nordwestlich des späteren Stadions (vom sog. Akropolishügel oder Macellum bis zum sog. Felsspalttempel; Abb. 1 Nr. 76. 78).

7 Die wichtigste Quelle zu diesen Ereignissen bleibt Herodots Lyder-Logos (Hdt. 1, 6-94). Zuletzt zusammenfassend zu König Kroisos mit der älteren Literatur DNP VI (1999) 858-860 s. v. Kroisos (P. Högemann). Für eine Diskussion der historischen Entwicklung vgl. W. Ellinger, Ephesos. Geschichte einer antiken Weltstadt ${ }^{2}$ (Stuttgart 1992) 33-47; Knibbe 1998, 83-94 und jetzt Scherrer - Trink1 2006, 261-267.

${ }^{8}$ Hdt. 1, 26.

${ }^{9} \mathrm{Zu}$ diesen Ereignissen vgl. Hdt. 1, 26; Polyain. 6, 50; Ail. var. 3, 26.

${ }^{10}$ In der Fachliteratur existieren für die mythische Gründung des attischen Königssohnes Androklos mehrere Bezeichnungen:

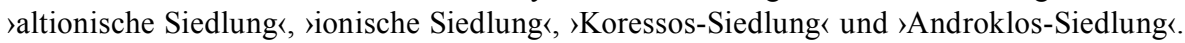

11 J. Keil, Zur Topographie und Geschichte von Ephesos, ÖJh 21/22, 1922-1924, 96-112; J. Keil, XII. Vorläufiger Bericht über die Ausgrabungen in Ephesos, ÖJh 23, 1926, Beibl. 250-256; J. Keil, XIV. Vorläufiger Bericht über die Ausgrabungen in Ephesos, ÖJh 25, 1929, Beibl. 33-38.

12 Über die topographischen Begriffe `Koressos`, `Tracheia` usw. und die exakte Lage der Siedlung wird in der Forschung immer noch diskutiert. Die vorgeschlagene Lokalisierung der topographischen Begriffe Tracheia und Koressos folgt Scherrer 1999, 381-383; Scherrer 2001, 60 f. Abb. 3, 1; Scherrer - Trink1 2006, 59. 261-264 Plan 3. In diesem Sinne auch Knibbe 1998, 74-77. Ähnlich auch H. Engelmann, Beiträge zur ephesischen Topographie, ZPE 89, 1991, 275-282. 286-292; Karwiese 1995, 19-27 Karte 1, jedoch mit wohl falscher Lokalisierung des Koressos-Hafens westlich des vom Panayırdağ vorspringenden Ausläufers nordwestlich des Stadions. H. Engelmann, Der Koressos, ein ephesisches Stadtviertel, ZPE 115, 1997, 131-135 und Kraft - Kayan - Brückner - Ripp 2000, 182-185 lokalisieren die altionische Siedlung im Nordosten des Panayırdağ, im Bereich des sog. Meterheiligtums. Für eine Übersicht zur Forschungsdiskussion um die Lage von Koressos vgl. M. Steskal, Die Geschichte der archäologischen Erforschung des Vediusgymnasiums und seines Umfeldes, in: M. Steskal - M. La Torre, Das Vediusgymnasium in Ephesos, ÖJh 70, 2001, 221-225. 231-234.

${ }^{13}$ In der bis zu $5 \mathrm{~m}$ hohen Auffüllungsschicht unter den Nutzungsniveaus des Vediusgymnasiums konnte Fundmaterial geborgen werden, das bis in spätgeometrische Zeit datiert. Vgl. dazu M. Steskal - S. Ladstätter, Vorbericht zur Baugeschichte des Vediusgymnasiums in Ephesos, ÖJh 73, 2004, 248 f. Gemäß M. Kerschner, Die Ionische Wanderung im Lichte neuer archäologischer Forschungen in Ephesos, in: E. Olshausen - H. Sonnabend (Hrsg.), »Troianer sind wir gewesen« - Migrationen in der antiken Welt. Akten des 8. internationalen Kolloquiums zur Historischen Geographie des Altertums, Stuttgart 2002, Geographica Historia 21 (2006) 367 Anm. 29 handelt es sich bei dem ältesten Fundstück um eine Vogelkotyle mit Mäanderhaken.

14 Vgl. dazu jetzt ausführlich Kerschner (Anm. 13) 364-382 bes. 366-369 mit der weiteren Lit. Vgl. dazu auch M. Büyükkolanc1, Excavations on Ayasuluk Hill in Selçuk/Turkey. A Contribution to the Early History of Ephesus, in: F. Krinzinger (Hrsg.), Die Ägäis und das westliche Mittelmeer. Beziehungen und Wechselwirkungen 8. bis 5. Jh. v. Chr. Akten des Symposions Wien 24. bis 27. März 1999, AForsch 4 = DenkschrWien 288 (Wien 2000) 39-43 und M. Büyükkolanc1, Apaša, das alte Ephesos und Ayasoluk, in: Cobet u. a. (Anm. 6) 21-26.

${ }^{15}$ Dadurch erklärt sich letztlich auch die durch die literarischen Quellen belegte, durch den archäologischen Befund aber bisher nicht nachweisbare Lokalisierung der frühesten ionischen Ansiedlung im Bereich des Panayırdağ. Die Bezeichnungen >altionische Siedlungく, >ionische Siedlungく und `Androklos-Siedlungく sollten aufgrund des archäologischen Befundes für diesen Siedlungsbereich jedoch vorerst keine Verwendung mehr finden.

${ }^{16}$ In der Folge als >Stadionhügel bezeichnet. 
Durch die militärische Intervention des Kroisos in die Defensive gezwungen, versuchte Pindaros, die Stadt mithilfe einer List vor dem ihr drohenden Schicksal zu bewahren. Er gab den Rat, die Akropolis durch Seile mit dem heiligen Bezirk des späteren Artemisions zu verbinden, um die Stadt auf diese Weise unter den Schutz der Göttin zu stellen ${ }^{17}$. Diese List blieb in der Folge nicht völlig wirkungslos. Kroisos nahm zwar die Akropolis ein, verschonte jedoch die $\operatorname{Stadt}^{18}$, u. a. auch deswegen, weil er dem Heiligtum mit einem Gelübde verpflichtet war ${ }^{19}$.

Die `Seilgeschichte< ist trotz ihres anekdotenhaften Charakters in mehrfacher Hinsicht von Bedeutung: Einerseits entspricht die Angabe von 7 Stadien (1 300 m) zwischen der Stadt und dem Artemision bei Herodot ${ }^{20}$ ungefähr der heutigen Entfernung zwischen dem späteren Artemision und der Nordwestflanke des Panayırdağ, womit die Deutung des $>$ Stadionhügels`als Akropolis der Siedlung untermauert wird ${ }^{21}$. Zum anderen gibt die Geschichte einen klaren Hinweis darauf, dass die Siedlung am Koressos noch nicht durch eine Heilige Straße mit dem späteren Artemision verbunden war, weshalb diese in der Not mit einem Seil sichtbar gemacht werden sollte. Dies stimmt letztlich auch mit dem archäologischen Befund überein: Der bisher archäologisch nachgewiesene Straßenabschnitt ${ }^{22}$ und die in diesem Zusammenhang errichtete Nekropole wurden nicht vor der Mitte des 6. Jahrhunderts v. Chr. angelegt, sondern in der Zeit nach der Einnahme der Stadt durch König Kroisos.

Die Machtübernahme durch Kroisos sollte für die Siedlung am Koressos nicht ohne Folgen bleiben, kam es doch kurz danach zu Machtkämpfen innerhalb der Führungselite der Polis ${ }^{23}$. Man sah sich deshalb veranlasst, den Athener Aristarchos für fünf Jahre mit uneingeschränkten Vollmachten auszustatten und ihn zu beauftragen, die ephesische Polisgemeinschaft neu zu ordnen ${ }^{24}$. Zur Schwächung des Einflusses lokaler Machthaber im Umland von Ephesos und zugunsten der Bildung eines politischen Machtzentrums scheint

${ }^{17}$ Hdt. 1, 26; Polyain. 6, 50 und Ail. var. 3, 26 beziehen sich wohl auf den ıStadionhügelı, der als Akropolis stärker befestigt gewesen sein dürfte. Eine etwas andere, m. E. zu stark auf Kroisos bezogene Interpretation bei Muss (Anm. 3) $27 \mathrm{f}$.

18 Polyain. 6, 50.

${ }^{19}$ Nikolaos von Damaskus, FGrHist 90 F 65. Ob in diesem Zusammenhang auch der Seiltrick eine gewisse Wirkung zeigte, muss offenbleiben, ist bei dem als sehr gottesfürchtig bekannten Kroisos jedoch nicht auszuschließen.

${ }^{20}$ Hdt. 1, 26.

${ }^{21}$ Vgl. dazu auch Karwiese 1995, 33; Kraft - Kayan - Brückner - Ripp 2000, 184 Abb. 6 lokalisieren die altionische Siedlung und die Akropolis im Bereich des Meterheiligtums, vor allem deswegen, weil sie die von Hdt. 1, 26 überlieferten sieben Stadien nicht als Angabe der Luftlinie zwischen Artemision und Akropolis, sondern als zu Fuß zurückgelegte Distanz verstehen, d. h. vom Artemision entlang der Küste bis zur altionischen Siedlung im Bereich des Meterheiligtums. Dieser Einwand mag zwar durchaus berechtigt sein, jedoch folgt die Distanzangabe bei Herodot unmittelbar auf die >Seilgeschichteく. Daher kann man sich fragen, ob Herodot die sieben Stadien nicht doch auf das Seil bezieht und die Strecke somit als Angabe der Luftlinie zwischen Akropolis und Artemision zu verstehen ist.

${ }^{22}$ Karwiese 1995, 27: »Die ältesten Funde, die bisher vom Prozessionsweg stammen, datieren aus dem 8. Jh., über das wir außer jetzt im Artemision - nicht hinauskommen.« Das Fundloch zwischen 1000 und 800 v. Chr. auf der vermuteten Akropolis und an der Prozessionsstraße sei auf »[...] den bisherigen ungünstigen Fundzufall zurückzuführen [...].« Vgl. jetzt jedoch St. Karwiese, Das Südtor der Tetragonos Agora in Ephesos. Die Archäologische Evidenz aus den Fundament-Sondierungen, ÖJh 66, 1997, Beibl. 253-318 mit dem stratigraphischen Befund und bes. 308: »Jedenfalls scheint der Betrieb der Prozessionsroute nach den ältesten im Südtorbereich angetroffenen Funden nicht vor dem späten 8. Jh. begonnen zu haben. Nach dem Evidenz-Ausschnitt im Südtor-Areal allerdings dürfte erst im 6. Jh. so etwas wie ein fester Weg entstanden sein."

${ }^{23}$ Kallimachos F 102 (= Aitia 8, 11): Nachdem Pindaros die Stadt verlassen hatte, tötete dessen Sohn einen gewissen Pasikles, einen Vertrauten des exilierten Tyrannen Pindaros. Vgl. dazu G. L. Huxley, The Early Ionians (London 1966) 109 f.; Muss (Anm. 3) 28. Allgemein erkennt man in Pasikles einen aisymnetes. Pasikles wird von Kallimachos jedoch als Archon bezeichnet, wobei sich nicht mehr entscheiden lässt, was mit dem Etikett Archon gemeint sein könnte - eine institutionalisierte Magistratur oder eine einer Tyrannis ähnliche Machtstellung. Vgl. dazu zuletzt K.-J. Hölkeskamp, Schiedsrichter, Gesetzgeber und Gesetzgebung im archaischen Griechenland, Historia Einzelschr. 131 (Stuttgart 1999) 109 f. mit der weiteren Lit.

${ }^{24}$ Suda s. v. Aristarchos E 3894. Aristarchos wurde gemäß dem synchronistischen Datum, das die Suda angibt, vor 553 v. Chr., als sich Kyros gegen Astyges erhob, von Verwandten nach Ephesos gerufen. Karwiese 1995, 36 und Knibbe 1998, 81 gehen davon aus, dass dieser von Kroisos selbst nach Ephesos geholt wurde. In der Forschung sieht man Aristarchos allgemein mit dem Amt des aisymnetes bekleidet. Vgl. dazu H.-J. Gehrke, Stasis. Untersuchungen zu den inneren Kriegen in griechischen Staaten des 5. und 4. Jahrhunderts v. Chr., Vestigia 35 (München 1985) 57; Muss (Anm. 3) 28; Karwiese 1995, 36; Knibbe 1998, 81; Rubinstein (Anm. 3) 1071; Scherrer - Trink1 2006, 262. Hölkeskamp (Anm. 23) 110-112 äußert hingegen nicht nur Bedenken dahingehend, dass Aristarchos den Titel aisymnetes innehatte, sondern zieht die Authentizität der Nachricht der Suda allgemein in Zweifel. Er schließt jedoch nicht aus, dass Aristarchos als neutraler >Schiedsrichter〈 und 〉Ordner nach Ephesos gerufen worden war, der mit konkreten Einzelmaßnahmen die Situation beruhigen sollte. 
es unter Aristarchos zudem zu einem Synoikismos der Siedlungen in der Chora von Ephesos gekommen zu sein ${ }^{25}$. Im Zuge dieser siedlungstopographischen und machtpolitischen Zentrumsbildung kam es wohl gleichzeitig zu einer Phylenreform, was sich zumindest aus den für Ephesos überlieferten Phylen- und Chiliastyennamen des 4. Jahrhunderts v. Chr. zu erschließen scheint ${ }^{26}$.

Es ist davon auszugehen, dass es um $560 \mathrm{v}$. Chr. infolge der militärischen und politischen Intervention des Kroisos zu einer umfassenden Neuordnung der ephesischen Polisgemeinschaft gekommen ist, welche nicht nur die Umsetzung politischer Ziele, sondern auch die Herausbildung eines siedlungstopographischen Zentrums zum Ziel hatte. Die wahrscheinliche Anlage einer Heiligen Straße, die überlieferte Aufgabe der Akropolis $^{27}$ und der anzunehmende Synoikismos der umliegenden Orte bieten diesbezüglich eindeutige Anhaltspunkte. In der Forschung wird deshalb zumeist postuliert, dass die Siedlung am Ayasoluk oder in der Ebene beim Artemision völlig neu errichtet wurde.

\section{Der archäologische Befund}

Als Indikatoren für eine am Ayasoluk oder in der Ebene beim Artemision liegende archaisch-klassische Siedlung lassen sich aus archäologischer Sicht bisher lediglich eine am östlichen Hangfuß des Ayasoluk aufgefundene Grabreihe (Abb. 1 Nr. 9), welche eine Belegung vom 7. bis zum 4. Jahrhundert v. Chr. zeigt ${ }^{28}$, sowie Sarkophagbestattungen des 5. Jahrhunderts v. Chr. ${ }^{29}$ unmittelbar außerhalb des zur byzantinischen Befestigung gehörenden `Tores der Verfolgung` (Abb. 1 Nr. 6) anführen ${ }^{30}$. Obwohl nun M. Kerschner und

${ }^{25}$ Dies ist in der Forschung unbestritten. Vgl. dazu Muss (Anm. 3) 28; Karwiese 1995, 33 f.; Knibbe 1998, 81; Scherrer 1999, 381; Scherrer - Trink1 2006, 267.

${ }^{26}$ Die Phylennamen lauten: Ephesoi, Bennaioi (Bennbinaioi), Teoi, Euonymoi und Carenaioi. Die altionischen Phylennamen werden in Ephesos zu Chiliastyennamen geändert: Geleontes, Argadeis, Oinopes, Boreis. Vgl. dazu O. Benndorf, Zur Ortskunde und Stadtgeschichte, in: FiE 1 (Wien 1906) 30; J. Keil, Die ephesischen Chiliastyen, ÖJh 16, 1913, 245-248; D. Knibbe, Neue ephesische Chiliastyen, ÖJh 46, 1961, Beibl. 19-32; Muss (Anm. 3) 28; Karwiese 1995, 36; Rubinstein (Anm. 3) 1072. Huxley (Anm. 23) 33 setzt die Phylenreform bereits unter Pythagoras an, Ephoros von Kyme, FGrHist 70 F 126, unter Androklos. Hölkeskamp (Anm. 23) 110-112 zweifelt hingegen daran, dass die Phylenreform unter Aristarchos stattfand. Hölkeskamp a. O. 111 lehnt es daher ab, dass mit der Phylenreform eventuell eine der konkreten Maßnahmen fassbar wird, durch welche die ephesische Polisgemeinschaft neu geordnet werden sollte: »Diese durchaus unterschiedlichen Reformen entziehen sich nämlich gerade der Einordnung in das Raster einer angeblich allgemeinen, geradezu panhellenischen, jedenfalls vielerorts und mit einer gewissen Regelhaftigkeit auftretenden Tendenz zur Neuordnung und/oder Erweiterung der Bürgerschaft und ihrer Unterabteilungen strukturell überall gleicher Art im 6. Jahrhundert, auf der solche Analogieschlüsse letztlich beruhen.« Dabei gilt es jedoch zu berücksichtigen, dass eine allgemeine und vielerorts bereits bewährte Reform geradezu prädestiniert ist, um als konkrete Einzelmaßnahme konkrete Probleme zu lösen. So ist in der Folge auch bei Hölkeskamp a. O. 111 zu lesen: »So war die Einführung einer neuen Einteilung der Bürgerschaft von Kyrene durch Demonax, die tatsächlich um die Mitte des 6. Jahrhunderts stattgefunden hat, ebenso durch eine besondere, untypische, wenn nicht einmalige Ausgangslage bedingt wie die späteren Reformen des Kleisthenes in Athen, deren Voraussetzungen wiederum spezifisch athenische waren und deren entscheidender Anlaß in einer außergewöhnlichen innenpolitischen Konstellation bestand.« Die Situation könnte nun in Ephesos ganz ähnlich gewesen sein. Der von Hölkeskamp nicht berücksichtigte Synoikismos, der damit verbundene Einzug von `neuen< Bevölkerungselementen sowie der archäologische Befund sprechen eine deutliche Sprache und lassen eine Phylenreform unter Aristarchos als durchaus plausibel erscheinen. Mit Hölkeskamp a. O. 111 f. ist allerdings anzunehmen, dass Aristarchos für Ephesos kaum eine >Verfassung`stiftete. Vielmehr ging es um die Durchsetzung konkreter Einzelmaßnahmen, welche von allen involvierten Parteien getragen wurden. Denn erst diese konnten der Verwirklichung der Pläne von König Kroisos zum Durchbruch verhelfen.

27 Polyain. 6, 50.

${ }^{28}$ Die Nekropole liegt an der alten Hauptstraße nach Izmir. Vgl. dazu C. İçten - A. Evren, Selçuk-Efes 3447 parsel kurtarma kazıs1, in: 8. Müze Kurtarma Kazıları Semineri (Ankara 1997) 85-110. Zum Fundmaterial vgl. jetzt auch Scherrer - Trink1 2006, 207.

${ }^{29}$ Diese Sarkophage wurden bei Bauarbeiten in der Nähe der seit Längerem bekannten mykenischen Bestattungen freigelegt. Dokumentation und Funde befinden sich im Efes Müzesi Selçuk. Vgl. dazu Scherrer - Trink1 2006, 261 mit Anm. 9, Plan 3 (mykenische Bestattungen).

${ }^{30}$ Die von J. Keil, XV. Vorläufiger Bericht über die Ausgrabungen in Ephesos, ÖJh 26, 1930, Beibl. $34-38$ erwähnten keramischen Funde aus einer Versuchsgrabung südlich des Artemisions können ebenso wenig als Hinweis auf eine in diesem Bereich zu lokalisierende Siedlung angeführt werden wie diejenigen von H. Brückner - W. W. Jungmann, Geologische Sondierungen, in: St. Karwiese und Mitarbeiter, Ephesos, ÖJh 65, 1996, Beibl. Grabungen 1995, 20 f. und İ. Kayan, Alluvial Geomorphology of the Küçük Menderes Plains and Geo-Archaeological Interpretations of the Site of Ephesos, in: Friesinger - Krinzinger 
M. Büyükkolancı am Ayasoluk die Aufdeckung archaischer und klassischer Funde in teilweise großer Menge gelang $^{31}$, kann dies für die Lokalisierung der griechischen Siedlung kein entscheidendes Argument sein. In der Forschung wird heute davon ausgegangen, dass der Ayasoluk »[...] bestenfalls an seinem küstenseitigen Hang $[\ldots] \ll \ll^{32}$ zum verbauten Siedlungsgebiet gehörte ${ }^{33}$. Hingegen stammen aus dem Gebiet der Siedlung am Koressos nicht nur eine ganz beachtliche Funddichte klassischer Artefakte ${ }^{34}$, sondern auch in situ vorgefundene Strukturen, welche auf eine rege Bauaktivität in der Zeit vor und nach der Einnahme der Siedlung durch König Kroisos schließen lassen ${ }^{35}$. Neben der bereits erwähnten Gräberstraße entwickelte sich an den Hängen über dem Koressos-Hafen seit dem mittleren 5. Jahrhundert v. Chr. - oder zumindest in dessen letztem Drittel - ein ausgedehnter Kultbezirk für verschiedene Gottheiten (Abb. 1 Nr. 13) ${ }^{36}$. Oberhalb dieses

(Anm. 5) 375 f., welche mittels geologischer Tiefenbohrungen geborgen wurden. Während man bei den von J. Keil geborgenen Keramikfragmenten nicht über die klassische Zeit hinauskommt, ist es im Falle der Bohrungen unklar, ob diese nicht innerhalb der Temenosgrenze vorgenommen wurden und die keramischen Funde daher dem Artemision zuzuordnen sind. Vgl. dazu die Temenosgrenze bei Hueber (Anm. 3) Abb. 48 sowie die Lage der Bohrpunkte bei Brückner - Jungmann a. O. Abb. 14 und Kayan a. O. Taf. 58. Hueber (Anm. 3) 38 und Scherrer 1999, 381 interpretieren diese Funde trotz fehlender architektonischer Überreste als Siedlungsbefunde, während die eigentliche griechische Stadt am Westhang des Ayasoluk vermutet wird. In diesem Sinne auch Kraft - Kayan - Brückner 1999, 96 Abb. 3; Kraft - Kayan - Brückner - Ripp 2000, 185 f. Abb. 6. 10; Kraft - Kayan - Brückner 2001, 123 Taf. 5. 6; Scherrer 2001, 60. Zur Lage der griechischen Stadt vgl. jetzt bes. Scherrer Trinkl 2006, 261: »[...] Lage, Struktur und Ausdehnung der Stadt in dieser Zeit sind aber wegen der $6 \mathrm{~m}$ hoch über dem klassischen Niveau in der Ebene beim Artemision liegenden Schwemmschicht unbekannt. Lediglich einige Funde klassischer Zeit am Ostrand von Selçuk entlang der Ausfallstraße nach Kuşadası und Magnesia, also ostsüdöstlich und westsüdwestlich des Artemisions, geben ungefähre Anhaltspunkte. Wie schon Strabons allgemein gehaltener Ausdruck, dass die Ephesier zur Zeit des Kroisos von den Bergen herabgestiegen seien, nahe legt, gehörte der Ayasoluk-Hügel jedenfalls nicht oder bestenfalls an seinem küstenseitigen Hang zum verbauten Stadtgebiet. Untersuchungen einiger Flächen im Übergangsbereich der Bergkuppe zu den beiden Hangseiten südlich der mittelalterlichen Zitadelle haben [...] nur vereinzelt klassische Streufunde erbracht.« Karwiese 1995, 34 lokalisiert die griechische Stadt hingegen am Osthang des Ayasoluk. In diesem Sinne auch Knibbe $1998,77$.

${ }^{31}$ Freundliche Mitteilung des ÖAI. Vgl. dazu jetzt auch Kerschner (Anm. 13) 367 mit Anm. 25.

${ }^{32}$ Scherrer - Trinkl 2006, 261.

${ }^{33}$ Auch bei diesen Funden lässt sich daher nicht ermitteln, ob sie im Zusammenhang mit dem unmittelbar benachbarten Artemision, der in der Ebene beim Artemision liegenden griechischen Stadt oder gar einer auf dem Ayasoluk liegenden archaischklassischen Siedlung zu interpretieren sind.

${ }^{34}$ Scherrer - Trinkl 2006, 263: »Ausgerechnet dieses Gebiet [der altionischen Siedlung] weist aber auch eine ganz beachtliche Funddichte klassischer Artefakte auf.« Vom sog. Akropolishügel stammt beispielsweise eine um 470 v. Chr. zu datierende Terrakotta-Peploskore (H. Vetters, Ephesos. Vorläufiger Grabungsbericht 1979, AnzWien 117, 1980, 253 Taf. 2; Scherrer - Trinkl 2006, 263 Abb. 237) und vom Embolos ein Urkundenrelief des späten 5. Jhs. v. Chr. (V. M. Strocka, Ein ephesisches Urkundenrelief, ÖJh 49, 1968-1971, 41-49). Bei Grabungen und Surveys fanden sich u. a. beim >Lukasgrab<, in der Umgebung des Staatsmarktes, unter dem Hof des Vediusgymnasiums und unter den Hanghäusern am Embolos immer wieder Streufunde klassischer Zeit. Vgl. dazu Steskal - Ladstätter (Anm. 13) 248 f.; B. Kratzmüller - E. Trink1, Von Athleten und Töpfern - ephesischen Bürgern auf der Spur, in: B. Brandt - V. Gassner - S. Ladstätter (Hrsg.), Synergia. Festschrift Friedrich Krinzinger I (Wien 2005) 157-167 und bes. Scherrer - Trinkl 2006, 208 mit Anm. 483-495; S. 267 mit der weiteren Lit.

${ }_{35}$ Der von Özyiğit (Anm. 3) 95 f. für die Stadtmauer vertretene chronologische Ansatz in klassische Zeit ist u. a. aus bautypologischen Gründen nicht zu halten. Vgl. dazu Th. Marksteiner, Bemerkungen zum hellenistischen Stadtmauerring von Ephesos, in: Friesinger - Krinzinger (Anm. 5) 413-419; Scherrer 2001, 62 f. mit Anm. 26. Zur hellenistischen Stadtmauer vgl. jetzt Groh (Anm. 3) 61-65.

${ }^{36}$ Zum sog. Meterheiligtum vgl. J. Keil, Denkmäler des Meter-Kultes, ÖJh 18, 1915, 66-78; Keil (Anm. 11:1926) 256-261; Ch. Börker - R. Merkelbach (Hrsg.), Inschriften griechischer Städte aus Kleinasien 12, 2. Die Inschriften von Ephesos II (Bonn 1979) Nr. 101-109; H. Engelmann - D. Knibbe - R. Merkelbach, Inschriften griechischer Städte aus Kleinasien 14, 4. Die Inschriften von Ephesos IV (Bonn 1980) Nr. 1215-1224; F. Naumann, Die Ikonographie der Kybele in der phrygischen und der griechischen Kunst, IstMitt Beih. 28 (Tübingen 1983) bes. 214-229; M. J. Vermaseren, Corpus Cultus Cybele Attidisque (CCCA) I. Asia minor, EPRO 50, 1 (Leiden 1987) 184-202; E. Heinzel, Der Kybelekult und die Dreigötterreliefs aus Ephesos, in: Scherrer - Taeuber - Thür (Anm. 5) 35-42; M. Büyükkolanc1, Ein Vierfigurenrelief des Meterkultes vom Panayırdağ in Ephesos, in: Scherrer - Taeuber - Thür (Anm. 5) 19-21; P. Scherrer, Felsheiligtum für die Göttermutter und Zeus, in: P. Scherrer (Hrsg.), Ephesos. Der neue Führer (Wien 1995) 62; Scherrer 1999, 383 f.; E. Vikela, Bemerkungen zur Topographie und Bildtypologie der Meter-Kybelereliefs: Vom phrygischen Vorbild zur griechischen Eigenständigkeit, AM 116, 2001, 67-123 bes. 108-111 Taf. 20, 3; Scherrer - Trink1 2006, 263. Eine Felsinschrift der Zeit um 400 v. Chr. markiert ein Heiligtum des Zeus Patroos (Börker - Merkelbach a. O. Nr. 104), eine vielleicht erst um 300 v. Chr. datierende Stele nennt Zeus Patroos zusammen mit Apollon Patroos (Börker - Merkelbach a. O. Nr. 102) und eine Inschrift des ausgehenden (?) 5. Jhs. v. Chr. gilt dem Zeus Mainalos (Scherrer 1999, 384; Scherrer - Trink1 2006,264 mit Anm. 43). Eine Gesamtvorlage unter Einschluss bisher unpublizierter Funde durch F. Soykal, Denkmäler des KybeleMeterkultes in Ephesos (Wien 1998) liegt als Wiener Dissertation vor, die dem Verfasser leider nicht zugänglich war. 
Kultbezirkes verläuft zudem eine in archaische Zeit bzw. um 500 v. Chr. datierte, zweischalige Quadermauer in Emplektontechnik, welche bis zum Beginn der Hafenbucht führt ${ }^{37}$. Insbesondere wurde im Bereich der Tetragonos Agora eine archaische Siedlung angeschnitten (Abb. 1 Nr. 49), an deren Stelle - offenbar nach einer gewissen siedlungschronologischen Lücke - im mittleren bis späten 5. Jahrhundert v. Chr. vier Becken sowie ein mindestens $5 \mathrm{~m}$ tiefer Brunnen angelegt worden waren. Aufgrund dieses archäologischen Befundes, welcher von P. Scherrer und E. Trinkl in mustergültiger Weise publiziert wurde ${ }^{38}$, lässt sich die Existenz einer archaisch-klassischen Siedlung im Bereich der hellenistisch-römischen Stadt nicht mehr bestreiten ${ }^{39}$. Zahlreiche Spuren einer kontinuierlichen Siedlungsaktivität von spätgeometrischer bis in archaisch-klassische Zeit gibt es zudem im Bereich des $>$ Vediusgymnasiums ${ }^{40}$. Die Lokalisierung der griechischen Stadt in der Ebene beim Artemision wird hingegen weiterhin als selbstverständlich vorausgesetzt, obwohl sich für die Interpretation der archäologischen und literarischen Quellen eine vollkommen andere - wie zu zeigen sein wird -, bessere Ausgangslage ergibt. Voraussetzung dafür ist, dass man diese archäologischen Zeugnisse als eindeutige Indizien für die Lage der griechischen Stadt interpretiert und daher auch das archaisch-klassische Ephesos im Bereich der hellenistischen Stadtanlage lokalisiert.

\section{Die Evidenz der Heiligen Straße}

Archaische Straßentrassen konnten bisher im Bereich der Tetragonos Agora, unter dem oft als >Sockelbau< bezeichneten Westchalkidikum der >Basilike Stoa< und im Ostbereich des Staatsmarktes archäologisch nachgewiesen werden (Abb. 1). Im Bereich der Tetragonos Agora stieß man in einer 1986 geöffneten Sondage auf das Stück einer mit Schotter verfestigten Straße, deren Orientierung deutlich vom Raster des hellenistisch-römischen Stadtplans abweicht ${ }^{41}$. Östlich der Straße wurden mehrere Gräber freigelegt, welche eine Belegung vom mittleren oder späten 6. Jahrhundert bis zum ausgehenden 4. Jahrhundert v. Chr. zeigen $^{42}$. In diesem Bereich verläuft die Straße von Südosten nach Nordwesten. Ihr weiterer Verlauf nach Norden ist archäologisch nicht eindeutig nachgewiesen, er dürfte jedoch in etwa demjenigen der vom Nordtor abgehenden hellenistisch-römischen Prozessionsstraße gefolgt sein: $\gg 8,10 \mathrm{~m}$ vom Nordtor wurde ein $2 \mathrm{~m}$ breiter Schnitt angelegt. Er ergab nach Abhebung des spätantiken Pflasters mehrere Aufschüttungsstraten und Tonrohrleitungen, die den alten Bestand der Straße bestätigen. « $^{43}$

\footnotetext{
${ }^{37}$ Die Datierung wurde mithilfe von Keramikfragmenten aus Probesondagen an der Mauer und auf dem Plateau hinter der Mauer gewonnen Vgl. dazu Keil (Anm. 11:1926) 261; F. Miltner, Ephesos. Stadt der Artemis und des Johannes (Wien 1958) 3 Abb. 1. Scherrer (Anm. 36) 62 datierte die Mauer in klassisch-hellenistische Zeit. Heute wird die als Wehrmauer angesprochene Struktur allgemein in archaische Zeit datiert. Vgl. dazu Scherrer 1999, 384; Scherrer 2001, 60 mit Abb. 3-4; Scherrer - Trink1 2006, 59 mit Plan 1, Nr. 6. Eine systematische Aufnahme der wenigen sichtbaren Reste der Innenbebauung ist bisher noch nicht erfolgt. Vgl. dazu Scherrer - Trinkl 2006, 59 mit Anm. 10.

${ }^{38}$ Scherrer - Trink1 2006, 59-148. 165-267.

39 Während Scherrer 1999, 384 diese archäologischen Funde noch mit dem Koressos-Hafen in Verbindung brachte, gehen jetzt auch Scherrer - Trink1 2006, 64. 264. 267 davon aus, dass an diesem Hafen in archaischer und klassischer Zeit eine Siedlung wohl ohne siedlungschronologische Unterbrechung existierte.

${ }^{40}$ Vgl. dazu Steskal - Ladstätter (Anm. 13) 248 f.

${ }^{41}$ Vgl. dazu H. Vetters, Ephesos. Vorläufiger Grabungsbericht 1986/87, AnzWien 125, 1988, 93; Scherrer - Trink1 2006,151 mit Plan 6. Dieser Straßenzug darf nicht mit der von G. Langmann bereits 1977 (H. Vetters, Ephesos. Vorläufiger Grabungsbericht 1977, AnzWien 115, 1978, 269; Vetters [Anm. 34] 254) im selben Bereich (von der Westseite der Rückwand der vermutlichen hellenistischen Oststoa begrenzt) angeschnittenen Straße verwechselt werden. Dieses Straßenstück wurde zwar immer wieder als archaisch bezeichnet (vgl. z. B. Knibbe - Langmann [Anm. 5] 53), spiegelt aber laut Scherrer - Trink1 2006, 151 Anm. 559 wohl den geänderten Verlauf der hellenistischen Zeit wider. Zum hellenistisch-römischen Stadtplan vgl. jetzt grundlegend Groh (Anm. 3).

${ }^{42}$ Vetters (Anm. 41:1978) 269 f.; H. Vetters, Ephesos. Vorläufiger Grabungsbericht 1978, AnzWien 116, 1979, 125 f.; Vetters (Anm. 34) 256; H. Vetters, Ephesos. Vorläufiger Grabungsbericht 1981, AnzWien 119, 1982, 70; Karwiese 1995, 34; Knibbe - Langmann (Anm. 5) 53; M. Kerschner u. a., Ephesos in archaischer und klassischer Zeit. Die Ausgrabungen in der Siedlung Smyrna, in: Krinzinger (Anm. 14) 47 und jetzt insbesondere Scherrer - Trink1 2006, 149-164.

${ }^{43}$ Vetters (Anm. 42:1982) 70.
} 
Südöstlich der Tetragonos Agora folgte die Straße der sog. Kuretenstraße (Abb. 1) ${ }^{44}$. So konnte die archaische Nekropole bisher im unteren Embolosbereich (sog. Auditoriumsgrabung) ${ }^{45}$ und im Bereich der sog. Kuretenhalle, an der Nordseite des unteren $>$ Embolos ${ }^{46}$, nachgewiesen werden. Es handelt sich hierbei ohne Zweifel um die Fortsetzung der im Bereich der Tetragonos Agora festgestellten Nekropole. Zu den Gräbern kommt noch ein weiterer wichtiger Befund: Unter der Anschüttung der Freitreppe des späthellenistischen Rundsockels (sog. Horologion) wurden die Reste einer schräg von Nordwesten nach Südosten verlaufenden Mauer aus Kalksteinquadern freigelegt ${ }^{47}$. Es handelt sich wohl um eine Art Hangbegrenzung der weiter südwestlich verlaufenden Straße.

Dass die Kuretenstraße immer den Verlauf der archaischen Straße respektierte, zeigt sich nicht nur an ihrer Lage innerhalb des sonst streng orthogonal ausgerichteten Stadtplans, sondern auch in dem Umstand, dass der Embolos weiterhin als Standort für Heroa und Grabmonumente ausgewählt wurde. Dies belegen die drei Heroa am Südwestende der `Neronischen Halle` und der im Osten gelegene `Memmiusbau (Abb. 1 Nr. 33$)^{48}$.

Die archaische Straßentrasse lässt sich in der Folge erneut im Bereich des Westchalkidikums der Basilike Stoa sowie im Osten des Staatsmarktes beobachten (Abb. 1 Nr. 29. 30 ${ }^{49}$. Die Straße scheint sich hier von ca. $3 \mathrm{~m}$ im Bereich des Westchalkidikums der Basilike Stoa auf ca. 3,2-3,5 m im Ostbereich des Staatsmarktes ${ }^{50}$ verbreitert zu haben. Die archaische Straße verlief demnach von der Kuretenstraße quer über den Staatsmarkt weiter nach Südosten. Zudem wurden unter dem Westchalkidikum der Basilike Stoa und im Osten des Staatsmarktes - in diesem Bereich auf beiden Seiten der Straße - ebenfalls archaische Gräber freigelegt ${ }^{51}$.

Es dürfte sich hier um die Fortsetzung der bereits auf der Tetragonos Agora und dem unteren Embolos angetroffene Nekropole handeln, d. h., diese Straße war - wohl zumindest bis in diesen Bereich - zur Gänze oder teilweise von Gräbern gesäumt ${ }^{52}$. Alle Gräber lassen sich nach Form und Ausstattung den Bestattungs-

${ }^{44}$ Das im Bereich der Celsusbibliothek angetroffene und von H. Vetters, Ephesos. Vorläufiger Grabungsbericht 1972, AnzWien 110, 1973, 181; H. Vetters, Ephesos. Vorläufiger Grabungsbericht 1973, AnzWien 111, 1974, 216; Vetters (Anm. 41:1978) 269 in archaische Zeit datierte Straßenstück dürfte nach dem keramischen Befund hingegen erst in augusteische Zeit zu datieren sein. Vgl. dazu jetzt Scherrer - Trink1 2006, 55 mit Anm. 272. Zum stratigraphischen Befund aus der Grabung im Bereich des Südtors der Tetragonos Agora vgl. Karwiese (Anm. 22) 295-298. 307 f. Zum weiteren Verlauf der Heiligen Straße vgl. auch Scherrer - Trink1 2006, 55. 154 f. Plan 6.

${ }^{45}$ Vetters (Anm. 41:1978) 267; W. Jobst, Embolosforschungen I. Archäologische Untersuchungen östlich der Celsusbibliothek in Ephesos. Mit einem Anhang (Fundbericht) von Ch. Schwanzar, ÖJh 54, 1983, Beibl. 171-177; H. Vetters, Ephesos. Vorläufiger Grabungsbericht 1982, AnzWien 120, 1983, 115 f.; Knibbe - Langmann (Anm. 5) 52 f.; Karwiese 1995, 34; Karwiese (Anm. 22) 279 mit Abb. 17; 295-297. 307 f.; Scherrer - Trinkl 2006, 149.

${ }^{46}$ H. Thür in: St. Karwiese und Mitarbeiter (Anm. 30) 14; H. Thür - W. Pietsch in: St. Karwiese und Mitarbeiter, Ephesos, ÖJh 66, 1997, Beibl. Grabungen 1996, 10; Thür (Anm. 5) 170. Eine in diesem Bereich aufgefundene Grube wird als archaische Grabgrube interpretiert. Laut Thür - Pietsch a. O. 10 ließen sich im Bereich der Kuretenhalle zwei archaische Gruben feststellten, eine ältere (die oben erwähnte Grabgrube?) sowie eine jüngere Lehmaufbewahrungsgrube. Es sei hier daher die Frage aufgeworfen, ob man diese `Lehmgrube< eventuell im Zusammenhang mit einem in diesem Bereich zu lokalisierenden Handwerkerquartier sehen könnte.

${ }^{47}$ Vetters (Anm. 45:1983) 116; Jobst (Anm. 45) 173-177.

${ }^{48}$ Vgl. dazu auch U. Outschar, Zum Monument des C. Memmius, ÖJh 60, 1990, 57-85.

49 Vgl. dazu F. Eichler, Die österreichischen Ausgrabungen in Ephesos im Jahre 1965, AnzWien 103, 1966, 11 f.; F. Eichler, Die österreichischen Ausgrabungen in Ephesos im Jahre 1966, AnzWien 104, 1967, 22-24; G. Langmann, Eine spätarchaische Nekropole unter dem Staatsmarkt zu Ephesos, in: Festschrift Fritz Eichler (Wien 1967) 104-123; F. Eichler, Die österreichischen Ausgrabungen in Ephesos im Jahre 1967, AnzWien 105, 1968, 83; H. Vetters, Ephesos. Vorläufiger Grabungsbericht 1971, AnzWien 109, 1972, 85; Vetters (Anm. 44:1973) 177. Auch in diesem Bereich wurde die nicht näher beschriebene StraBenbegrenzung freigelegt.

${ }^{50}$ Vetters (Anm. 44:1973) 177: »Die Straße war in diesem Bereich [Westchalkidikum Basilike Stoa], wie St. Karwiese vermutet, schmäler (etwa $3 \mathrm{~m}$ ) als im SO-Bereich des Staatsmarktes.« Die Straße dürfte in Analogie zu dem auf der Tetragonos Agora freigelegten Stück ca. 3,2 m breit gewesen sein.

${ }^{51}$ Eichler (Anm. 49:1966) 11 f.; Eichler (Anm. 49:1967) 22-24; Langmann (Anm. 49) 104-123; H. Vetters, Ephesos. Vorläufiger Grabungsbericht 1970, AnzWien 108, 1971, 92 f.; Vetters (Anm. 49:1972) 85; Vetters (Anm. 44:1973) 177; V. MitsopoulouLeon, Ein Grabfund des vierten vorchristlichen Jahrhunderts aus Ephesos, ÖJh 50, 1972-1975, 252-265; D. Knibbe, Neue Inschriften aus Ephesos IV, ÖJh 50, 1972-1975, Beibl. 20 f.; Börker - Merkelbach (Anm. 36) Nr. 110. 115; H. Philipp, Archaische Gräber in Ostionien, IstMitt 31, 1981, 149-166; Özyiğit (Anm. 3) 83-96; Knibbe - Langmann (Anm. 5) 52; Karwiese 1995, 34; Scherrer - Trink1 2006, 55. 149.

${ }^{52}$ Weitere Gräber wurden im Bereich der Hanghäuser (S. Fabrizii-Reuer, Die menschlichen Skelette aus den Hanghäusern von Ephesos, AnzWien 130, 1993, 25-40) und unter der südlichen Hanghausstraße freigelegt (H. Vetters, Ephesos. Vorläufiger 
sitten des kleinasiatischen Küstengebietes in archaischer Zeit zuordnen ${ }^{53}$. Die Straßentrassen wurden - ohne eine genauere Stratigraphie zu veröffentlichen - in archaische Zeit datiert ${ }^{54}$, durch die Untersuchungen von St. Karwiese beim Südtor der Tetragonos Agora $^{55}$ liegt nun aber zumindest für diesen Bereich eine genauere stratigraphische Untersuchung vor. So ist das sog. Stratum 1 im Bereich des Südtores der Tetragonos Agora, aus welchem die ältesten Funde stammen, in das 6. Jahrhundert v. Chr. zu datieren ${ }^{56}$. Der von Mauern begrenzte Weg aus kleinen, festgestampften Steinen ${ }^{57}$ wurde demnach wohl kurz vor der Mitte des 6. Jahrhunderts v. Chr. angelegt ${ }^{58}$. Dieser Zeitraum wird durch die Datierung der frühesten Gräber bestätigt, deren Anlage entlang der Straße um die Mitte des 6. Jahrhunderts v. Chr. anzusetzen ist.

D. Knibbe und G. Langmann entwickelten aufgrund dieses Befundes die These einer uralten Ringnekropole, die bereits in archaischer Zeit einer Heiligen Straße rund um den Panayırdağ folgte: »Die alte Ringnekropole wurde zum Vehikel der Ausdehnung ihrer [der Artemis] Macht, zu ihrer via triumphalis, die sie durch Altäre an >strategisch « wichtigen Punkten sicherte. Der erste mag dort gestanden sein, wo sie, von ihrem Heiligtum am Ayasoluk kommend, den Rundweg an der Nordseite des Panayırdağ erreichte, der zweite (?) und wichtigste stand zweifellos bei der Triodos an der Abzweigung nach Ortygia, der dritte (?) schließlich stand auf der Sattelhöhe zwischen Panayır- und Bülbüldağ [...]..159

Eine rund um den Berg verlaufende Heilige Straße lässt sich jedoch erst für die römische Zeit nachwei$\operatorname{sen}^{60}$. Zu einem früheren Zeitpunkt wäre dieser Verlauf auch nicht möglich gewesen: Die Region nördlich des Panayırdağ war erst zu Zeiten der späten Republik soweit verlandet, dass die Anlage einer Straße in diesem Bereich überhaupt möglich wurde ${ }^{61}$. Zudem gibt es für die Existenz früher Gräber im Norden, Osten und Süden bisher keine Beweise. Da die frühesten Gräber erst um die Mitte des 6. Jahrhunderts v. Chr. zu datieren sind, fehlt jeglicher Hinweis darauf, dass die Ephesier ihre Toten schon seit jeher an diesem Platz begraben hätten.

Abgesehen von der Tatsache, dass es weder für die oben aufgeführten Altäre noch für den skizzierten Verlauf der archaischen Heiligen Straße einen archäologischen Nachweis gibt, lässt sich eine solche Sicht der Dinge - bei gleichzeitiger Lokalisierung der griechischen Siedlung beim Artemision - auch nicht mehr mit der erst vor Kurzem entdeckten archaisch-klassischen Nekropole östlich des Ayasoluk vereinbaren. Daher kommt P. Scherrer zu dem Schluss, dass man »[...] die bisherige Sichtweise einer Prozessionsroute als Begräbnisstraße [...] «2 ${ }^{62}$ aufzugeben habe. Vielmehr wird diese Gräberstraße jetzt als Teil der Fernstraße von Ephesos nach Pygela (Kuşadası) interpretiert, von welcher an der Stelle des augusteischen Agora-Südtors eine Küstenstraße abbog und am Westfuß des Panayırdağ in das Gebiet der Siedlung am Hafen Koressos bzw. der Tracheia führte ${ }^{63}$. Eine nach Pygela (Kuşadası) und weiter entlang der Küste nach Süden zum

Grabungsbericht für die Jahre 1984 und 1985, AnzWien 123, 1986, 97 mit Taf. 21). Im Bereich der Tetragonos Agora wurden zudem Funde von vorhellenistischen Gräbern in sekundärer Verwendung gemacht. Vgl. dazu Karwiese (Anm. 22) 279 mit Abb. 17; D. Knibbe - B. İplikçioğlu, Neue Inschriften aus Ephesos VIII, ÖJh 53, 1981/1982, 150 Nr. 170 (archaische Grabinschrift für Preychos); W. Alzinger, Ritzzeichnungen in den Marmorbrüchen von Ephesos, ÖJh 48, 1966/1967, 71; V. M. Strocka, Neue archaische Löwen in Anatolien, AA 1977, 507-510 (archaischer Grablöwe); Börker - Merkelbach (Anm. 36) Nr. 112. 124 (klassische Grabinschriften). Für die genauen Fundorte vgl. Scherrer - Trinkl 2006, 149 Anm. 555.

${ }^{53}$ Vgl. dazu zusammenfassend Philipp (Anm. 51) 149-166; Scherrer - Trink1 2006, 158-162.

54 Vgl. z. B. Vetters (Anm. 51:1971) 93: »Aus den oberen Straten wurden hellenistische Scherben, aus dem Straßenkörper archaische Keramikbruchstücke geborgen."

${ }_{55}$ Vgl. dazu Karwiese (Anm. 22:1997) 253-318; vgl. auch V. Gassner, Das Südtor der Tetragonos-Agora. Keramik und Kleinfunde, FiE 13, 1, 1 (Wien 1997) 25-32.

${ }^{56}$ Karwiese (Anm. 22) 296 f.

57 Eichler (Anm. 49:1968) 83.

58 So auch Karwiese (Anm. 22) 308; Scherrer - Trink1 2006, 55. 151.

59 Knibbe - Langmann (Anm. 5) 11.

${ }^{60}$ Knibbe - Langmann (Anm. 5); Knibbe - Thür (Anm. 5); Knibbe (Anm. 5) 449-454; Thür (Anm. 5) 163-172; Groh (Anm. 3) 107 f. mit Abb. 19. 20.

${ }^{61}$ Kraft - Kayan - Brückner - Ripp 2000, 187: »The summation of sedimentary environmental and geomorphic data in stratigraphic section figure 9 and the map interpretation figure 10 in relationship to the >Feigengarten excavation< and the Artemision show that until the end of the late Roman Republic the only viable route of the Via Sacra from the Lysimachean city is via the southeast flank of Mount Pion [...].«

${ }^{62}$ Scherrer 1999, 385.

${ }^{63}$ Vgl. dazu jetzt ausführlich Scherrer - Trinkl 2006, 55. 150 f. mit Plan 6. 
Panionion führende Fernstraße läßt sich für archaisch-klassische Zeit jedoch ebenso wenig nachweisen wie der Beginn »[...] des von der (alten) Triodos westwärts nach Ortygia führenden Astes des Prozessionsweges. $\aleph^{64}$. Im Bereich des dreibogigen Agora-Südtors (Abb. 1 Nr. 49) befand sich nämlich bis ungefähr zur Zeitenwende der `Dreiweg` und der Beginn des Prozessionsweges nach Ortygia, dem legendären Geburtsort der Artemis und des Apollon ${ }^{65}$. Auch wenn die Existenz einer Straßengabelung im Bereich des augusteischen Agora-Südtores bereits in archaischer Zeit freilich nicht auszuschließen ist ${ }^{66}$, soll diese Gräberstraße als Teil einer Heiligen Straße interpretiert werden, welche die westlich und südwestlich des Koressos-Hafens liegende Stadt des Kroisos mit dem extraurbanen Artemision verband ${ }^{67}$. Eine solche Interpretation des archäologischen Befundes kann sich nicht nur auf einen Vergleich mit den im selben zeitlichen und geographischen Horizont angelegten Heiligen Straßen auf Samos sowie zwischen Milet und Didyma stützen. Insbesondere lässt sich daran auch die Interpretation aller anderen, in Bezug auf die Lokalisierung der archaisch-klassischen Siedlung von Ephesos relevanten archäologischen und literarischen Quellen anschließen.

In Analogie zu anderen Heiligen Straßen ${ }^{68}$ ist davon auszugehen, dass die Heilige Straße von Ephesos beim Koressos-Hafen, der zu dieser Zeit ohne Zweifel ein wichtiger Ankerplatz war, ihren Anfang nahm und von dort Richtung Tetragonos Agora führte (Abb. 1). Ihr weiterer Verlauf vom Koressos-Hafen nach Süden lässt sich möglicherweise sogar aus den hellenistisch-römischen Straßenzügen rekonstruieren, wenn man dabei das Phänomen berücksichtigt, dass der Verlauf Heiliger Straßen oft bis in römische Zeit respektiert und nur unwesentlich verändert wurde ${ }^{69}$. So bietet sich als mögliche Alternative die hellenistischrömische Prozessionsstraße an, welche vom Gebiet des ehemaligen Koressos-Hafens direkt zur Tetragonos Agora führt, die wiederum von der archaischen Heiligen Straße nachweislich gequert wurde (Abb. 1). Im Bereich der Celsusbibliothek bog die Straße nach Südosten ab, indem sie der Kuretenstraße folgte und anschließend quer über den Staatsmarkt weiter zum Artemision führte (Abb. 1); in diesem Bereich hatte die archaische Heilige Straße eindeutig den Charakter einer Gräberstraße. Zur Nekropole, die unter der Tetragonos Agora freigelegt wurde, kommen weitere Bestattungen der vorlysimachischen Zeit im Gebiet südlich der Agora, zwischen der sog. Celsusbibliothek und der Kuretenstraße. Weitere Gräber sind im Areal der Hanghausgrabungen, unter dem Westchalkidikum der Basilike Stoa am obersten Ende der Kuretenstraße sowie in der Umgebung des Staatsmarktes zu finden.

Über den weiteren Verlauf und die Ausstattung der archaischen Heiligen Straße außerhalb der griechischen Stadt ist leider nichts bekannt. Dies gilt insbesondere für die Eintrittssituation in das Temenos sowie für deren Verlauf und die Ausstattung innerhalb des Artemisheiligtums.

Der einzig mögliche weitere Verlauf der Heiligen Straße vom Staatsmarkt führt - wie auch geologische und paleogeographische Untersuchungen bestätigen $-»[\ldots]$ across the delta-floodplain of the Marnas and Selinus Rivers skirting the Sacred Harbor and thence to the western entrance to the Artemision complex « ${ }^{70}$. Eventuell führte die Heilige Straße bereits im 6. Jahrhundert v. Chr. am Osthang des Panayırdağ vorbei (Abb. 1 Nr. 13), wo sich dann folgerichtig spätestens seit dem 5. Jahrhundert v. Chr. ein ausgedehnter Kultbezirk für verschiedene Gottheiten entwickelte ${ }^{71}$.

${ }^{64}$ Knibbe - Langmann (Anm. 5) 53.

${ }^{65}$ Vgl. dazu D. Knibbe, Der Staatsmarkt. Die Inschriften des Prytaneions, die Kureteninschriften und sonstige religiöse Texte, FiE 9, 1, 1 (Wien 1981) 70-79; H. Thür, Das Hadrianstor von Ephesos, FiE 11, 1 (Wien 1989) 25 f.; Knibbe 1998,36 f.; Scherrer - Trink1 2006, 55. In Folge der Errichtung des Agora-Südtores wurde der `Dreiweg` an die Stelle des (späteren) Hadriantores verlegt.

${ }^{66}$ In diesem Sinne Scherrer - Trink1 2006, 55. Vgl. dazu auch Groh (Anm. 3) 68 mit Abb. 11, 1.

${ }^{67}$ Auch Scherrer - Trinkl 2006, 55 gehen davon aus, dass diese Straße »[...] auf das Artemision und die am Ostrand der ephesischen Bucht vorbeiführende Hauptstraße von Sardes bzw. Smyrna nach Magnesia [...]« zielte.

${ }_{68}$ Als Beispiel sei hier die Heilige Straße von Milet genannt, welche im Bereich des sog. Löwenhafens ihren Anfang nahm. Vgl. dazu Herda (Anm. 6) 259 f. mit Abb. 12; Schneider (Anm. 6) 102-105. Den Hafen als Ausgangspunkt lässt sich - wie sich im Rahmen meiner Lizentiatsarbeit herausstellte - mit guten Gründen auch für die Heilige Straße von Samos postulieren.

${ }^{69}$ Vgl. dazu beispielsweise die Heilige Straße von Athen nach Eleusis (J. Travlos, Bildlexikon zur Topographie des antiken Attika [Tübingen 1988] 177-190) oder diejenige von Samos (Kyrieleis - Kienast - Weisshaar [Anm. 6] 391-404. 432-445).

${ }^{70} \mathrm{Kraft}$ - Kayan - Brückner - Ripp 2000, 187.

${ }^{71}$ Scherrer - Trinkl 2006, 264 f. interpretieren die archäologischen Quellen, d. h. die seit dem 4. Jh. v. Chr. im Bereich der altionischen Siedlung belegte Verehrung von Apollon Patroos, Zeus Patroos, Zeus Mainalos und Athena, als Zeichen dafür, dass dieses Gebiet als Ort für die Rückbesinnung auf attische oder im weiteren Sinne griechische Traditionen diente, und gewinnen 


\section{Die Bedeutung der Siedlung Smyrna und des Koressos-Hafens}

Im Jahre 1987 wurden unter dem Westteil der Tetragonos Agora architektonische Überreste einer im späten 8. Jahrhundert v. Chr. angelegten Siedlung entdeckt, welche infolge übereinstimmender Angaben bei Strabon $^{72}$ heute einhellig als Siedlung Smyrna bei Ephesos identifiziert werden (Abb. 1 Nr. 49) ${ }^{73}$. Während die archaische Zeit mit mindestens fünf größeren Bauphasen belegt ist, sind aus klassischer Zeit keine Wohnhäuser bekannt. Allerdings liegt genügend Material des 5. und 4. Jahrhunderts v. Chr. vor, »[...] um einen kontinuierlichen Verlust von Keramik in der weiteren Umgebung und damit den prinzipiellen Fortbestand der Siedlung als gesichert annehmen zu dürfen. $\mathbb{1}^{74}$. Im mittleren bis späten 5. Jahrhundert v. Chr. erfolgte an derselben Stelle der Bau von vier in den Boden eingetieften, viereckigen Becken sowie eines mindestens $5 \mathrm{~m}$ tiefen Brunnens. Dieser Komplex bestand bis in das erste Viertel des 4. Jahrhunderts v. Chr. und diente gewerblichen Zwecken. Der für das mittlere 6. Jahrhundert v. Chr. festzustellende Abbruch der Wohntätigkeit wird daher als eine Aufgabe des meeresnahen Areals ${ }^{75}$ für Wohn-, aber nicht für weniger heikle Wirtschaftszwecke interpretiert ${ }^{76}$.

Auch wenn nun diese Siedlungsreste tatsächlich mit dem >alten< Smyrna zu identifizieren sind ${ }^{77}$, ergibt sich bei einer Lokalisierung des archaisch-klassischen Ephesos in unmittelbarer Nähe von Smyrna, und nicht in $2 \mathrm{~km}$ Entfernung, eine vollkommen andere und bessere Ausgangslage für die Interpretation der schriftlichen und archäologischen Quellen. Was die Siedlungsreste von Smyrna betrifft, soll an dieser Stelle als Erster Strabon zu Wort kommen:

»Dies sind die zwölf ionischen Städte. Hinzugenommen in den Ionischen Bund wurde späterhin noch Smyrna. Das geschah auf Betreiben der Ephesier: sie wohnten nämlich von alters mit ihnen zusammen, in der Zeit als Ephesos auch Smyrna hieß (und Kallinos gibt der Stadt gewissermaßen diesen Namen wenn er in der Rede zu Zeus die Ephesier Smyrnäer nennt:

Der Smyrnäer erbarm dich [...]

Es gab auch eine Örtlichkeit in Ephesos, die Smyrna hieß, wie Hipponax zeigt:

Und wohnen tat er hinter der Stadt in Smyrna, in

Der Gegend zwischen Tracheia und von Lepre Akte.

[...] Smyrna lag also bei dem heutigen Gymnasion hinter der damaligen Stadt und rzwischen Tracheia und Lepre Akte׳. Die Smyrnäer verließen dann die Ephesier und zogen gegen den Ort an dem jetzt Smyrna liegt $[\ldots]$. « $^{78}$

Es ist auffallend, dass Strabon Smyrna immer in einem Atemzug mit Ephesos nennt. Dadurch entsteht der Eindruck, dass Smyrna nicht mehr eine eigenständige Polis oder Kome darstellte, sondern folgerichtig im Zuge des Synoikismos unter Kroisos mit Ephesos, welches sich bis dahin an den nördlichen Abhängen und auf dem Panayırdağ befand, vereint worden war. Andernfalls bleibt die weitere Existenz eines unab-

daher aus den Quellen den Eindruck, »[...] als bildeten der Koressoshafen und die zugehörige Siedlung einen literarischen Topos für die den Griechen bzw. Athen gegenüber freundlich eingestellt Partei in Ephesos.«

${ }^{72}$ Strab. 14, 1, 4.

${ }^{73}$ G. Langmann, Ephesos, ÖJh 59, 1989, Beibl. Grabungen 1988, 8; G. Langmann - P. Scherrer, Ephesos, ÖJh 62, 1993 , Beibl. Grabungen 1992, 12-14; P. Scherrer in: St. Karwiese und Mitarbeiter, Ephesos, ÖJh 63, 1994, Beibl. Grabungen 1993, 11-14; P. Scherrer in: Karwiese und Mitarbeiter (Anm. 46) 5 f.; Scherrer (Anm. 36) 146-148; Scherrer 1999, 385-387; M. Kerschner u. a., Ephesos in archaischer und klassischer Zeit. Die Ausgrabungen in der Siedlung Smyrna, in: Krinzinger (Anm. 14) 45-54 und jetzt insbesondere die umfassende Publikation Scherrer - Trink1 2006, 59-148. 165-267.

${ }^{74}$ Scherrer - Trink1 2006, 64.

${ }^{75}$ Für den Verlauf der Küstenlinie in archaisch-klassischer Zeit in diesem Bereich vgl. H. Brückner, Geoarchäologische Forschungen in der Westtürkei - das Beispiel Ephesos, in: T. Breuer (Hrsg.), Geographische Forschung im Mittelmeerraum und in der Neuen Welt, Passauer Schriften zur Geographie 15 (Passau 1997) 39-51 bes. 44 f.; J. C. Kraft - H. Brückner - İ. Kayan, The Sea under the City of Ancient Ephesos, in: Brandt - Gassner - Ladstätter (Anm. 34) 149-151 Abb. 1-3.

${ }^{76}$ Zum Wechsel der hydrologischen Verhältnisse vgl. Scherrer - Trink1 2006, 146-148.

${ }^{77}$ Für eine Interpretation der schriftlichen Quellen zur Lage von Smyrna vgl. jetzt Scherrer - Trink1 2006, 60. Hingegen ist für Kerschner (Anm. 13) 367 Anm. 28 »die von Langmann und Scherrer vertretene Identifizierung mit der von Strab. 14, 1, 4 erwähnten Siedlung Smyrna [...] nicht gesichert.«

${ }^{78}$ Strab. 14, 1, 4. Übersetzt nach Radt 2005, 6 f. 
hängigen Smyrna, bei gleichzeitigem Synoikismos der umliegenden Orte, nur schwer erklärbar. Wie nicht anders zu erwarten, hielten sich die ehemaligen Bewohner weiterhin an die alten Ortsnamen und Bezeichnungen der beiden ursprünglich unabhängigen Orte. Es kam zu einer Durchmischung, die sich nicht nur bei Strabon zu erkennen gibt, sondern sich auch in dem von Strabon zitierten Gedicht des Hipponax (ca. 540 v. Chr.) widerspiegelt; Kallinos (ca. 650 v. Chr.) dürfte sich allerdings auf das noch >unabhängige< Smyrna bezogen haben.

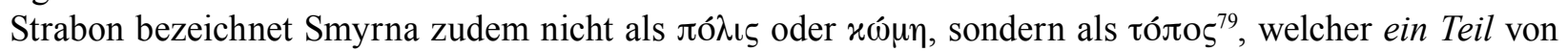
Ephesos war. Er beruft sich auf eine zeitgenössische Quelle, nämlich auf Hipponax, aus dessen Gedicht sich Smyrna ebenfalls nicht als unabhängige Polis oder Kome, sondern eben nur als ein Platz hinter der damaligen Stadt verstehen lässt. Das Zusammenleben und die Austauschbarkeit der Ortsbezeichnungen bei Strabon können erst durch eine solche Interpretation wörtlich genommen und dadurch überhaupt verständlich werden. Damit bleibt in diesem Zusammenhang lediglich noch auf die Feststellung Strabons einzugehen, Smyrna sei in den Ionischen Bund aufgenommen worden ${ }^{80}$. Dies wiederum setzt in jedem Fall die Existenz einer unabhängigen Polis Smyrna voraus. Strabon bezieht sich mit dieser Aussage allerdings nicht auf das ephesische, sondern auf das neugegründete Smyrna, das - laut ihm - dem Bund erst später und auf Veranlassung seiner salten Mitbewohnerı, der Ephesier, beitrat.

Interpretiert man nun den archäologischen Befund von Smyrna - der Quelle folgend - als südlichstes

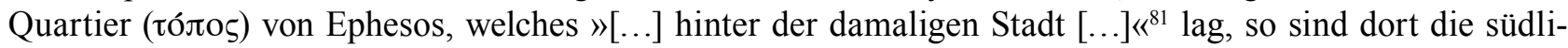
che Stadtgrenze der griechischen Siedlung und der Beginn der Heiligen Straße außerhalb der Siedlung zu lokalisieren. Im Osten der Heiligen Straße liegt in diesem Bereich - soweit ich sehe - die weiter im Norden nicht mehr angetroffene Nekropole und im Westen das südlichste Quartier der griechischen Stadt. Interessanterweise wurde das Quartier im früheren bis mittleren 6. Jahrhundert v. Chr. aufgegeben und erst später wieder als Handwerkerquartier benutzt, d. h., auch im Wohnbereich scheint es zu einer Umstrukturierung und Neuorganisation gekommen zu sein. Zudem fügt sich die Lage des Handwerkerviertels am südlichen Rand der Siedlung und in unmittelbarer Nähe zu der hier beginnenden Nekropole einwandfrei in die übliche Konzeption archaischer Städte ein ${ }^{82}$.

Aufgrund dieses Befundes ergibt sich m. E. ein klares Bild der Siedlungsstruktur: Infolge der militärischen Intervention des Königs Kroisos kam es zu einer Neukonzeption der in diesem Bereich bereits bestehenden Siedlungen. Die Akropolis und die Siedlung oberhalb des Koressos-Hafens mussten aufgegeben werden, während das Stadtgebiet durch den Synoikismos - zumindest mit der Siedlung Smyrna - nach Süden erweitert wurde. Die Siedlung westlich und südwestlich des Koressos-Hafens blieb bestehen. Als Folge dieser Umstrukturierungen kurz vor oder um die Mitte des 6. Jahrhunderts v. Chr. wurde auch die Heilige Straße erbaut. Die Nekropole legte man dabei unmittelbar am Stadtrand, im Osten der Heiligen Straße an. Im Westen der Straße dürfte später das möglicherweise außerhalb des eigentlichen Stadtgebietes liegende Handwerkerviertel angelegt worden sein. Die Nekropole folgte, wohl auch aufgrund der eher beschränkten Platzverhältnisse zwischen Panayırdağ und Bülbüldağ, der Heiligen Straße nach Südosten. Die Gräber zeigen eine Belegung von der Mitte des 6. Jahrhunderts v. Chr. bis in das 4. Jahrhundert v. Chr. und können damit problemlos mit einer archaisch-klassischen Siedlung Ephesos/Smyrna westlich und südwestlich des Koressos-Hafens in Verbindung gebracht werden. Die Gräber unter der Tetragonos Agora weisen zudem eine in den lydischen Raum weisende Tumulusform auf. Das könnte darauf hinweisen, dass sich die Bewohner von Smyrna in der Nähe ihrer ehemals unabhängigen Siedlung bestatten ließen.

Diese Annahme gewinnt dadurch an Bedeutung, dass man diese Nekropole als diejenige der griechischen Stadt um das Artemision am Ayasoluk ansprach ${ }^{83}$. So mag man sich fragen, weshalb die Ephesier ihre Toten so weit von ihrer Stadt entfernt und erst noch in unmittelbarer Nachbarschaft einer anderen Siedlung, der allgemeinen Meinung nach unabhängigen Polis Smyrna, hätten begraben sollen. Es ist daher

\footnotetext{
79 Strab. 14, 1, 4 .

${ }^{80}$ Strab. 14, 1, 4.

${ }^{81}$ Strab. 14, 1, 4. Übersetzt nach Radt 2004, 7.

82 Vgl. dazu F. Lang, Archaische Siedlungen in Griechenland. Struktur und Entwicklung (Berlin 1996) 129-131 in Bezug auf Töpfereien, die meist außerhalb der Stadtmauern lagen. Handwerkerquartiere in unmittelbarer Nähe zu einer Nekropole sind bis jetzt erst für geometrische und klassische Zeit bekannt; vgl. dazu Lang a. O. 131 mit Anm. 845.

${ }^{83}$ Vgl. dazu Knibbe - Langmann (Anm. 5) 11. 53; Karwiese 1995, 34; Karwiese (Anm. 22) 307 f.; Knibbe $1998,93$.
} 
nicht weiter verwunderlich, dass die Nekropole aufgrund dieser Erklärungsschwierigkeiten sowohl Ephesos als auch Smyrna ${ }^{84}$, heute jedoch Smyrna sowie weiteren Dorf- und Streusiedlungen zugewiesen wird, von denen eine am Hang des Bülbüldağ oberhalb des Staatsmarktes lokalisiert wird ${ }^{85}$. Geht man hingegen davon aus, dass die Nekropole unmittelbar am Stadtrand von Ephesos begann, wobei Smyrna das südlichste Quartier ( braucht man anzunehmen, dass der Synoikismos des Kroisos nicht alle Siedlungsplätze lückenlos erfasst hätte, wie dies bisher geschah; oder dass bald darauf an den alten Siedlungsplätzen mit ihren Häfen und anderen natürlichen Vorteilen erneut Ansiedlungen entstanden wären ${ }^{86}$.

Die Lage der Nekropole am Osthang des Ayasoluk und der Sarkophagbestattungen unmittelbar außerhalb des Tores der Verfolgung kann hingegen tatsächlich durch die große Fernstraße von Smyrna/Izmir nach Magnesia am Mäander erklärt werden. So ist diese Nekropole auch südlich des Artemisions zu verfolgen $^{87}$, wo die Straße anscheinend auf ähnlicher Route wie die Eisenbahnstrecke heute entlangführte ${ }^{88}$.

Der ursprüngliche Verlauf der Heiligen Straße in östlicher Richtung sowie ihre bereits in archaischer Zeit große Bedeutung spiegeln sich hingegen noch deutlich in der Neuanlage der hellenistischen Stadt und in dem Umstand, dass der Embolos weiterhin als Prozessionsstraße sowie als Standort für Heroa und Grabmonumente diente ${ }^{89}$. Andernfalls wäre der Verlauf der archaischen Straße kaum respektiert und in das ${ }^{84}$ Vgl. dazu Knibbe - Langmann (Anm. 5) 11. 53; Karwiese 1995, 34; Knibbe 1998, 77. 81. Die Konfusion erreicht ihren Höhe-
punkt in der Aussage von Knibbe - Thür (Anm. 5) 23: »Ältere Straßenführungen, die das Artemision in hellenistischer Zeit
mit der lysimachischen Stadt und vorher mit ihren archaischen und klassischen Vorgängersiedlungen Smyrna (unter der helle-
nistisch-römischen Agora) und der zum Koressos-Hafen gehörigen Siedlung auf dem sog. Akropolishügel verbunden haben,
sind mit Sicherheit anzunehmen, müssen jedoch etwa 30 m südlicher, unmittelbar am Fuß des Panayırdağ verlaufen sein;
leider unterbindet die moderne Asphaltstraße jegliche archäologische Untersuchung in diesem Bereich. Konnte die archaische
Prozessionsstraße aus diesem Grunde außerhalb der hellenistisch-römischen Stadt noch nirgends archäologisch festgestellt
werden, so wurde sie sehr wohl innerhalb der Stadt, und zwar im südöstlichen Bereich der Agora und vor der Celsusbibliothek
sowie im östlichen Bereich des >Staatsmarktes` durch Gräber archaischer Zeit nachgewiesen, die auf diese Straße orientiert
sind.« An dieser Stelle sei daher die Frage aufgeworfen, ob die griechische Stadt ihrer Meinung nach jetzt dennoch nicht beim
Artemision lag. Auch die von Scherrer 1999,385 getroffene Annahme, dass es sich bei den Nekropolen auf der Tetragonos
Agora und derjenigen im Bereich des Staatsmarktes um zwei Nekropolen verschiedener Siedlungen gehandelt hat, vermag
nicht einzuleuchten. So wurden alle Gräber entlang einer Straße angelegt, wobei die archaischen Gräber am unteren Embolos
und diejenigen im Bereich des Westchalkidikums der Basilike Stoa lediglich ca. 100 m voneinander entfernt liegen. Zudem
behielt der Embolos bekanntlich bis in hellenistisch-römische Zeit seinen Charakter als Begräbnisstraße. Auch wenn sich
entlang des Embolos keine weiteren archaischen Gräber nachweisen ließen - die oben erwähnten Sondagen und Funde schei-
nen jedoch das Gegenteil anzudeuten -, so lassen die enge räumliche Distanz und die absolut gleichen Bestattungsformen m.
E. nicht auf zwei verschiedene Nekropolen zweier Siedlungen schließen.

${ }^{85}$ So Scherrer - Trink1 2006, 267.

${ }^{86}$ Scherrer - Trinkl 2006, 267: »Der für die Stadtgeschichte von Ephesos bisher als Fixpunkt angesehene Synoikismos des Kroisos scheint bei weitem nicht so lückenlos alle Siedlungsplätze erfasst zu haben, wie bisher angenommen, oder es entstanden bald darauf an den alten Siedlungsplätzen mit ihren Häfen und anderen natürlichen Vorteilen neuerlich Ansiedlungen. Verstärkt wird diese Befundung durch die kontinuierliche Fortführung der Bestattungen im Ostteil der Agora, am Embolos und am >Staatsmarkt<, wobei die Ausdehnung der Nekropole die Benutzung durch weitere Dorf- oder Streusiedlungen nahe legt, von denen eine wohl am Hang des Preon (Bülbüldağ) oberhalb des `Staatsmarktes` zu lokalisieren ist.«

${ }^{87}$ Für undatierte Felsgräber am Delikli Kaya vgl. die Karte von A. Schindler als Beilage in FiE 1 (Wien 1906). Spätarchaischfrühklassische Gräber wurden zudem im Seitental dahinter, dem Ab-i-Hayat, aufgefunden (Özyiğit [Anm. 3] 83-96) und vom Tavşantepe stammt ein unfertiger, von S. Erdemgil - A. Evren, Efes Tavşantepe Aslan1, TürkAD 30, 1992, 71-82 in spätklassisch-frühhellenistische Zeit datierter Grablöwe, der wohl einem Grabbau an dieser Fernstraße zuzuschreiben ist. Zu dieser Nekropole vgl. auch Scherrer - Trink1 2006, 261.

${ }^{88}$ Zum Verlauf dieser Fernstraße vgl. Scherrer - Trink1 2006, 261.

89 Der Grund für die Anlage der archaischen Heiligen Straße von der Siedlung und dem Heiligtum weg ließe sich hingegen nur dann erklären, wenn man annimmt, dass der erst für römische Zeit, belegbare Prozessionsweg nach Ortygia bereits in archaischer Zeit bestand und nach Hunderten von Jahren plötzlich reaktiviert wurde. So A. Bammer - U. Muss, Das Artemision von Ephesos. Das Weltwunder Ioniens in archaischer und klassischer Zeit, AW Sonderh. (Mainz 1996) 23 Abb. 18; Thür (Anm. 5) 170. Auch hier fehlt jedoch jeglicher Beweis dafür, dass es eine solche Verbindung nach Ortygia bereits in archaischer Zeit gegeben hat und wenn ja, ändert sich dadurch nichts an der oben angeführten Argumentation. Zudem scheint der Verlauf des bisher bekannten Abschnittes der archaischen Heiligen Straße im Bereich der Tetragonos Agora einen weiteren Verlauf nach Norden anzudeuten. Die ursprüngliche Richtung der Heiligen Straße nach Osten spiegelt sich weiter deutlich in der Neuanlage der hellenistischen Stadt. Der Verlauf der archaischen Straße wurde respektiert und in das sonst orthogonale Straßensystem eingefügt. 
sonst orthogonale Straßensystem eingefügt worden. Da die Nekropole entlang der Heiligen Straße eine Belegung von der zweiten Hälfte des 6. Jahrhunderts v. Chr. bis in das 4. Jahrhundert v. Chr. zeigt, rundet sich damit das Bild einer archaisch-klassischen Siedlung im Bereich der hellenistisch-römischen Stadt ab; ebenso dasjenige einer damit verbundenen Neukonzeption von Siedlung, Heiliger Straße und Nekropole durch König Kroisos.

Schließlich spricht insbesondere auch die Lage des Koressos-Hafens aufgrund verkehrspolitischer und siedlungstechnischer Überlegungen für eine Lokalisierung der griechischen Stadt in unmittelbarer Nähe dieses Ankerplatzes, da sich der direkte und gemäß den Quellen wichtigste Zugang zum Meer andernfalls nicht bei der Siedlung befunden hätte ${ }^{90}$. Aus welchem Grund Kroisos die Siedlung von den günstigen Ankerplätzen im Westen und der damit strategisch besten Lage in das verlandende und überschwemmungsgefährdete Mündungsgebiet der umliegenden Flüsse hätte verlegen sollen (Abb. 1), wird in der Forschung denn auch nicht weiter angesprochen ${ }^{91}$.

Die Existenz eines nahen und günstig gelegenen Hafens war für die Siedlung ohne Zweifel von zentraler Bedeutung. Dies umso mehr, als Ephesos der Endpunkt eines Karawanenweges aus dem Osten war, mit dem auch ein Arm der persischen Königsstraße zusammenfiel ${ }^{92}$. Der Seehandel und der Umschlag von Gütern dürfte demnach - neben dem reichen Hinterland und dem Artemision - ein wichtiger Faktor der ökonomischen Lebensgrundlage der Stadt gebildet haben ${ }^{93}$. Schließlich sei in diesem Zusammenhang auf die Frage hingewiesen, ob der Koressos-Hafen in archaisch-klassischer Zeit überhaupt direkt vom Artemision oder von einer in diesem Bereich liegenden Siedlung her zugänglich war. Das Meer dürfte zu dieser Zeit nämlich bis an den nordöstlichen Ausläufer des Panayırdağ, hinter welchem der gut geschützte Hafen lag, gereicht haben (Abb. 1) ${ }^{94}$. Der Hafen wäre somit einzig von der Siedlung westlich des späteren Stadions direkt zu erreichen gewesen, während die Verbindung zum Artemision durch die Heilige Straße im Süden und Osten des Berges gewährleistet war (Abb. 1).

Von einer Abzweigung nach Ortygia ist hingegen auch für hellenistische Zeit nichts bekannt. In diesem Sinne wäre dann der archaische Prozessionsweg nach Ortygia in hellenistischer Zeit zu einer Heiligen Straße geworden, durch die sie gemäß Hueber (Anm. 3) $42 »[\ldots]$ demonstrativ an das Artemision gebunden« war. Dasselbe ist nun jedoch aus guten Gründen bereits für die archaische Zeit anzunehmen, während es zu einer umfassenden Erweiterung des >Prozessionsnetzes` erst in römischer Zeit kam.

90 Bezeichnenderweise lässt sich laut Scherrer - Trinkl 2006, 262 ein in der Nähe der archaisch-klassischen Siedlung beim Artemision liegender Hafen weder benennen noch präziser lokalisieren. Zur Problematik der Lokalisierung des nur bei Kreophylos (FGrH 417 F 1) genannten Heiligen Hafens vgl. jetzt Scherrer - Trinkl 2006, 262 Anm. 15.

${ }^{1}$ Während früher die eigentliche griechische Stadt am West- oder Osthang des Ayasoluk vermutet wurde, wird heute davon ausgegangen, dass der eigentliche Wohnbereich in der Ebene des Artemisions lag. Karwiese 1995, 34 verweist zwar auf die siedlungstechnisch äußerst schlechte Lage im Mündungsgebiet des Marnas, was in gewisser Weise in direktem Gegensatz zu derjenigen von Karwiese 1995, 65 steht, wo er in Berufung auf den Lexikon-Artikel `Ephesos« von Stephanos von Byzanz festhält, dass die Stadt aufgrund ihrer tiefen Lage den winterlichen Überschwemmungen durch Kaystros und Marnas ausgesetzt gewesen sei. In dieser Textstelle ist m. E. eher ein Reflex der von Strab. 14, 1, 21 im Zusammenhang mit der lysimachischen Neugründung überlieferten >Überschwemmungsgeschichteく zu erkennen.

92 RE Suppl. XII (1970) 270 s. v. Ephesos (D. Knibbe); L. Casson, The Ancient Mariniers. Seafarers and Sea Fighters of the Mediterranean in Ancient Times (New York 1959) 179.

${ }_{93}$ So auch H. Zabehlicky, Die Grabungen im Hafen von Ephesos 1987-1989, in: Friesinger - Krinzinger (Anm. 5) 480. Die große Bedeutung des ephesischen Hafens für Gesandtschaftsreisen und Güteraustausch unterstreichen jetzt auch Scherrer - Trinkl 2006, 262 mit Anm. 14 mit der weiteren Lit.

${ }_{94}$ Vgl. dazu Kraft - Kayan - Brückner - Ripp 2000, 212 Taf. 6 (Archaic coastline); 219 Taf. 10; 187: »The summation of sedimentary environmental and geomorphic section figure 9 and the map interpretation figure 10 in relationship to the $>$ Feigengarten excavation< and the Artemision show that until the end of the late Roman Republic the only viable route of the Via Sacra from Lysimachean city is via the southeast flank of Mount Pion [...].« 


\section{Die literarische Überlieferung}

Bei den wichtigsten Quellen zur Lage der archaisch-klassischen Siedlung ${ }^{95}$ handelt es sich um die zeitgenössische Beschreibung des Überfalls des Atheners Thrasyllos auf Ephesos im Jahre 409 v. Chr. bei Xenophon ${ }^{96}$ sowie um Aufzeichnungen in einem ägyptischen Papyrus ${ }^{97}$. Aus diesen Quellen geht nicht nur hervor, dass die Stadt bei einem Hügel lag - bei dem es sich eigentlich nur um den Panayırdağ, und nicht den Ayasoluk gehandelt haben kann -, sondern auch, dass die Stadt wohl in unmittelbarer Nähe des Koressos-Hafens lag:

»Und nachdem er [Thrasyllos] die Hopliten beim Koressos hatte an Land gehen lassen, die Reiter aber, Pelasten, Schiffssoldaten und alle übrigen bei dem Sumpfgelände auf der anderen Seite der Stadt, führte er mit Tagesanbruch die beiden Heere heran. [...] Diese alle zogen zuerst zur Abwehr gegen die Hopliten auf dem Koressos; nachdem sie diese in die Flucht geschlagen, ungefähr 100 von ihnen getötet und sie bis zur Küste verfolgt hatten, wandten sie sich gegen diejenigen, welche bei dem Sumpf standen. « $^{98}$

Der Koressos-Hafen blieb demnach weiterhin ein Hauptankerplatz der archaisch-klassischen Siedlung. So erwähnt ihn auch Herodot als Ankerplatz der Ionier bei ihrer Expedition gegen Sardes im Jahre 498 v. Chr. ${ }^{99}$. Aus Xenophons Bericht scheint zudem hervorzugehen, dass sich oberhalb des Hafens eine gleichnamige Anhöhe befand, von welcher aus Thrasyllos seine Hopliten gegen Ephesos ziehen ließ. Diese Abteilung des athenischen Heeres muss gemäß der Schilderung Xenophons für die Stadt eine unmittelbare Bedrohung dargestellt haben, sonst wären die Ephesier und ihre Verbündeten kaum als Erstes gegen die dort stationierten Truppen vorgegangen. Die Hopliten befanden sich bei einer Lokalisierung der archaischklassischen Siedlung westlich und südwestlich des Koressos-Hafens wohl auf der nördlichen Hügelkuppe des Panayırdağ. Die andere Abteilung stand hingegen im Küstenbereich westlich des Artemisions, um die Stadt >von der anderen Seite her - allenfalls über die Heilige Straße - anzugreifen (Abb. 1). Eine solche Sicht der Dinge bestätigt die minutiöse Schilderung im ägyptischen Papyrus über das Vordringen der ersten athenischen Angriffseinheit bis direkt an die Stadt heran:

»Als sie aber gelandet waren, führte er die gesamte Streitmacht vor die Stadt. Die Ephesier und die anwesenden Lakedaimonier konnten zwar die athenischen Truppen unter Pasion nicht sehen (sie waren nämlich noch weiter entfernt, weil sie einen längeren Weg als die anderen genommen hatten), aber sie sahen

${ }_{95}$ Die Zusammenstellung der literarischen Quellen zur Lage der archaisch-klassischen Siedlung von Ephesos - Xenophon, die Hellenika von Oxyrhynchos, Strabon und Kreophylos - erfolgt nach chronologischen Gesichtspunkten, indem die zeitgenössische Beschreibung des Überfalls des Atheners Thrasyllos auf Ephesos im Jahre 409 v. Chr. bzw. die diesbezüglichen Aufzeichnungen in der Hellenika von Oxyrhynchos den Ausgangspunkt bilden. Die Glaubwürdigkeit dieser beiden Texte ist betreffend des historischen Ereignisses und der topographischen Angaben als hoch einzustufen, da sich die beiden in sinnvoller Weise ergänzen. So hält auch E. Rung, Xenophon, the Oxyrhynchus Historian and the Mission of Timocrates in Greece, in: Ch. Tuplin (Hrsg.), Xenophon and his World. Papers from a conference held in Liverpool in July 1999, Historia Einzelschr. 172 (Stuttgart 2004) 424 in Bezug auf die sowohl von Xenophon als auch in der Hellenika von Oxyrhynchos überlieferte Unternehmung des Timokrates in Griechenland fest: »So I conclude that the two Greek traditions about Timocrates' mission to Greece do not contradict each other. The sources in question complement each other on the circumstances and results of the mission.« Für eine quellenkritische Diskussion von Xenophons Hellenika vgl. Ch. Tuplin, Xenophon and his World: An Introductory Review, in: Tuplin a. O. 13-31. - Für die Lokalisierung der von Strabon und Kreophylos überlieferten topographischen Fixpunkte vgl. bes. Scherrer 1999, 381-383; Scherrer 2001, 60 f. Allgemein gilt es festzuhalten, dass die Lokalisierung der in der literarischen Überlieferung genannten topographischen Fixpunkte derjenigen in der Forschung zur historischen Topographie von Ephesos allgemein akzeptierten folgt. Vgl. dazu etwa Scherrer 1999, 381-383; Scherrer 2001, 60 f.; Scherrer - Trinkl 2006, 261-264. Die von der gängigen Meinung abweichende Lokalisierung der archaisch-klassischen Siedlung ergibt sich hingegen einzig aus einer textimmantenen Diskussion der relevanten Quellentexte.

${ }^{96}$ Xen. hell. 1, 2, 7-10.

${ }^{97}$ Hell. Oxyrh. 1 f. Zum Text vgl. G. A. Lehmann, Ein neues Fragment der Hell. Oxy.: Einige Bemerkungen zu P. Cairo (temp. inv. no.) 26/6/27/1-35, ZPE 26, 1977, 181-191 bes. 187 mit Anm. 20 (= Papyrus Col. I 16 f.) und jetzt R. Behrwald (Hrsg.), Hellenika von Oxyrhynchos, Texte zur Forschung 86 (Darmstadt 2004). Für eine Interpretation der historischen Ereignisse vgl. Karwiese 1995, 51 f.; Scherrer - Trink1 2006, 262-264.

98 Xen. hell. 1, 2, 7-10. Übersetzt nach G. Strasburger (Hrsg.), Xenophon. Hellenika (München 1988) 21. 23.

${ }^{99}$ Hdt. 5, 100. 
jene unter Thrasyllos, die gerade angekommen waren. Sie griffen sie an dem Koressos genannten Hafen an, und hatten dabei jene als Verbündete, die ihnen früher schon geholfen hatten [---]. [...] Danach, als Thrasyllos, der Stratege der Athener, zur Stadt kam, ließ er einige Soldaten angreifen, die anderen aber führte er selbst auf den Hügel hinauf, der hoch und kaum zu besteigen ist. Und sowohl die einen, schon innerhalb der Stadt, als auch die anderen außerhalb wurden zum Rückzug gezwungen. $\ll^{100}$

Die von Xenophon geschilderte Zangenbewegung, welche die Stadt zu Fall bringen sollte, wird durch die oben angeführte Textstelle nicht nur bestätigt, sondern dahin präzisiert, dass die athenischen Truppen unter Pasion einen weiteren Weg bis zur Stadt zurückzulegen hatten als diejenigen unter Thrasyllos. Geht man hingegen davon aus, dass die griechische Siedlung in der Ebene beim Artemision zu lokalisieren ist und stationiert demzufolge die beiden athenischen Truppenteile am Koressos sowie nördlich des Ayasoluk ${ }^{101}$, so ist genau das Gegenteil der Fall (Abb. 1) ${ }^{102}$. Zudem bleibt unklar, wie Thrasyllos, der laut Xenophon bei Tagesanbruch »beide« Truppenteile an die Stadt heranführte, dies bei der sich ergebenden räumlichen Distanz hätte bewerkstelligen sollen.

Während Xenophon in der Folge von nur einer Kampfhandlung am Koressos berichtet, scheint der Papyrustext in diesem Punkt genauer zu sein. Demnach erfolgte das erste Aufeinandertreffen bereits am Koressos-Hafen. Den Ephesiern und ihren Verbündeten gelang es jedoch nicht, die Athener schon am Hafen zurückzuschlagen. An dieser Stelle ergibt sich bei einer Lokalisierung der griechischen Stadt in der Ebene beim Artemision das Problem, dass man gezwungen ist, auf dem Koressos einen Wachposten zu vermuten und die Verteidiger innert kürzester Zeit von dem über $1 \mathrm{~km}$ entfernten Stadtgebiet dorthin ausrücken zu $\operatorname{lassen}^{103}$. Gemäß dem Papyrustext sahen hingegen die Ephesier und die anwesenden Lakedaimonier die Athener unter Thrasyllos am Koressos-Hafen an Land gehen, um in der Folge die Athener ohne Erfolg anzugreifen. Thrasyllos gelangte zur Stadt und ließ einige Soldaten die Stadt angreifen, während er selbst auf einem hohen Hügel Stellung bezog. Bei diesem Hügel kann es sich nur um die nördliche Hügelkuppe des Panayırdağ und kaum um den Ayasoluk handeln ${ }^{104}$. Zum einen lässt sich kaum erklären, wie es Thrasyllos und seine Truppen anstellten, unbehelligt auf den über $2 \mathrm{~km}$ entfernten Ayasoluk zu gelangen und welchen strategischen Vorteil diese Truppenbewegung hätte bringen sollen, zumal dieses Vorgehen praktisch zu einer Vereinigung der beiden Truppenteile geführt hätte. Zum anderen wurde dieser Truppenteil nach Xenophon ganz eindeutig am Koressos in die Flucht geschlagen. Es liegt daher auf der Hand, dass Xenophon die anfängliche Niederlage der Ephesier am Koressos-Hafen nicht erwähnt, sondern lediglich auf deren Sieg auf der nördlichen Hügelkuppe des Panayırdağ, welcher in der Antike ebenfalls Koressos genannt wurde, eingeht ${ }^{105}$. Folgerichtig errichteten die Ephesier, nachdem sie auch den zweiten Truppenteil

\footnotetext{
100 Übersetzt nach Behrwald (Anm. 97) 33.

101 So Karwiese 1995, 51.

102 Zudem ist der Bezugspunkt - die griechische Stadt - durch den Papyrustext (Hell. Oxyrh. 1, 1) genau definiert, führte doch Thrasyllos als Erstes »[...] die gesamte Streitmacht vor die Stadt.« Übersetzt nach Behrwald (Anm. 97) 33.

${ }_{103}$ So Karwiese 1995, 51.

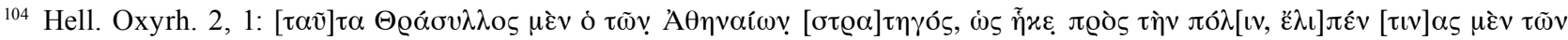

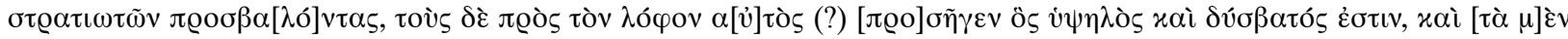

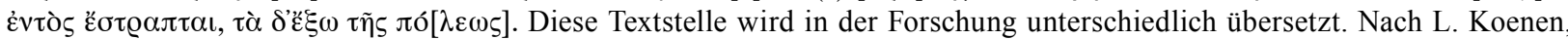
Papyrology in the Federal Republic of Germany and Fieldwork of the International Photographic Archive in Cairo, Studia

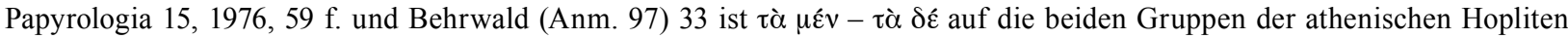
zu beziehen, nach Lehmann (Anm. 97) 187 Anm. 20 hingegen auf die stadteinwärts bzw. -auswärts verlaufende Hangseite

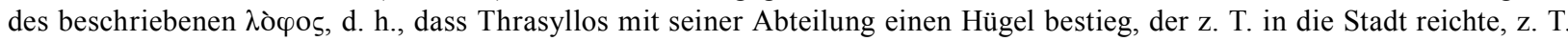
jedoch außerhalb lag. Laut Karwiese 1995, 51 und Scherrer 1999, 381, die der Übersetzung von Lehmann folgen, passt diese topographische Angabe einzig auf den Ayasoluk. Die Textstelle lässt sich m. E. jedoch auch in diesem Fall ohne Probleme auf den Panayırdağ beziehen: So musste man im Zuge der Eroberung des Kroisos lediglich die Höhensiedlung, d. h. die Akropolis auf dem >Stadionhügel< und den Bereich über den Hängen des Koressos, aufgeben. Dieser Teil des Hügels lag demnach außerhalb der Siedlung, während der vom Panayırdağ vorspringende Ausläufer nordwestlich des späteren Stadions (die Tracheia) weiterhin ein Teil der griechischen Siedlung blieb und demnach innerhalb der Stadt lag (Abb. 1).

105 FGrH 417 F 1; Strab. 14, 1, 21.
} 
unter Pasion in die Flucht geschlagen hatten ${ }^{106}$, eines der beiden Siegesdenkmale nicht auf dem Ayasoluk, sondern am Koressos ${ }^{107}$.

Bei der zweiten Hauptquelle zur Lokalisierung der archaisch-klassischen Siedlung von Ephesos handelt es sich um Strabon, welcher im Anschluss an die Beschreibung der topographischen Lage der Stadt bis zur militärischen Intervention des Kroisos anmerkt: »[...] Androklos vertrieb sie und siedelte die meisten der mit ihm Gekommenen bei dem Athenaheiligtum und der Hypelaios an, wobei er auch ein Stück von dem Berghang bei Koressos zu der Stadt zog. Bis zu den Ereignissen zur Zeit des Kroisos wurde die Stadt so bewohnt, später aber kamen sie von dem Berghang herab und wohnten bis Alexander um das heutige Heiligtum. $\ll^{108}$

Auch in dieser Textstelle erkennt man - wohl zu Recht - den Hinweis auf einen Synoikismos der umliegenden Orte ${ }^{109}$. Hingegen enthält die Passage keinen Anhaltspunkt, aus dem auf eine Umsiedlung der Bevölkerung und eine Neugründung der Stadt um das Artemision ${ }^{110}$ geschlossen werden könnte, wie sie in der Forschung vorgeschlagen und meist vorbehaltlos akzeptiert werden. Eine erste Ungereimtheit ergibt sich bereits aus der oben zitierten Textstelle. So ist daraus nicht a priori zu entnehmen, dass Strabo mit [...]

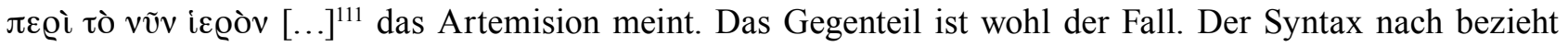
sich Strabon auf das kurz vorher erwähnte Athenaheiligtum, um das die altionische Siedlung gelegen haben soll. Auf das Artemision kommt er erst etwas später ausführlich zu sprechen ${ }^{112}$. Zu der fraglichen Textstelle findet sich in Strabons Werk zudem eine exakte Parallele - im Zusammenhang mit dem Ionischen Bund geht er bereits früher genauer auf die Topographie von Ephesos ein: »Die Stadt lag ehemals bei dem Athenaheiligtum, das heute außerhalb der Stadt bei der sogenannten Hypelaios liegt [...]. $\ll^{113}$

Es ist auffallend, dass Strabon, der hier auf die Lage der altionischen Siedlung eingeht, später in Bezug

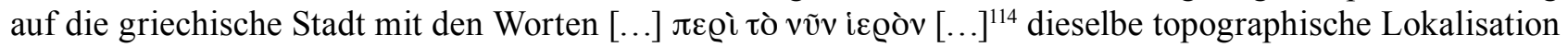
der Stadt zu wiederholen scheint. Demnach ist davon auszugehen, dass auch die archaisch-klassische Siedlung den alten Siedlungsbereich z. T. miteinschloss. Die Stadt lag um das Heiligtum (der Athena), welches sich jetzt (in römischer Zeit) außerhalb der Stadt befindet.

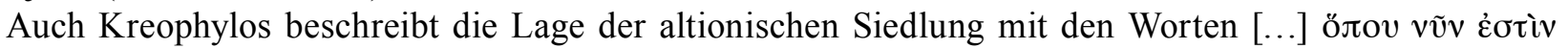

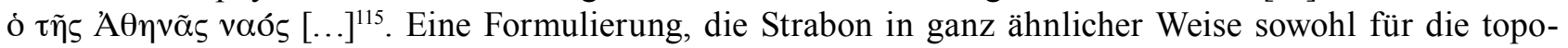
graphische Lage der altionischen als auch für diejenige der griechischen Siedlung verwendet. Die Lage des Athenaheiligtums, wo es sich jetzt in Bezug auf die hellenistisch-römische Siedlung befindet, scheint demnach ein zentraler Punkt für die Beschreibung der Topographie der beiden Vorgängersiedlungen gewesen zu sein. Strabon und Kreophylos beziehen sich mit dem Wort »jetzt« immer auf das Athena-, jedoch keineswegs auf das Artemisheiligtum. Dieser topographischen Angabe entsprechend, lag auch die griechische Stadt $»[\ldots]$ um das heutige Heiligtum [...] «116, womit nur das Athenaheiligtum gemeint sein kann.

Allerdings muss dieses Athenaheiligtum keineswegs bereits zu Zeiten des Kroisos oder gar der altionischen Siedlung bestanden haben. Naheliegender ist, wie P. Scherrer davon auszugehen, dass sich dieses »jetzt« auf einen zu Zeiten des Kreophylos und Strabons noch bestehenden oder zumindest noch im

106 Xen. hell. 1, 2, 9. In diesem Zusammenhang werden in der Hell. Oxyrh. 2, 2 zwei Straßen erwähnt, welche die Athener nach ihrer Niederlage als Fluchtwege wählten. Die eine führte zum Meer, die andere wird als »obere Straße« bezeichnet. Diese Straßen könnten nun - bei der oben vorgeschlagenen Lokalisierung der Ereignisse - mit dem zum Koressos-Hafen führenden Teil der Heiligen Straße oder mit demjenigen, welcher südlich um den Panayırdağ Richtung Artemision führte, gleichgesetzt werden. Leider lässt sich aus dem Papyrustext nicht mehr erschließen, auf welche Truppenteile der Athener diese Textstelle $\mathrm{zu}$ beziehen ist.

107 Xen. hell. 1, 2, 10.

108 Strab. 14, 1, 21. Übersetzt nach Radt 2005, 23.

109 Knibbe 1998, 81.

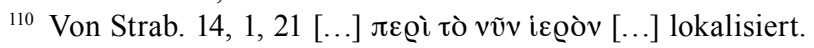

111 Strab. 14, 1, 21.

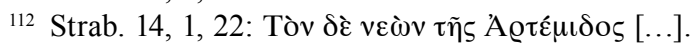

113 Strab. 14, 1, 4. Übersetzt nach Radt 2005, 7.

114 Strab. 14, 1, 21.

${ }^{115}$ FGrH 417 F 1.

116 Strab. 14, 1, 21. Übersetzt nach Radt 2005, 23. 
Bewusstsein verankerten Tempelbau bezieht ${ }^{117}$. Damit konnte dem Leser ein noch existenter Fixpunkt - wie er »jetzt« in Bezug auf die römische Stadt liegt - für die genaue Lokalisierung des archaisch-klassischen Siedlungsgebietes vor Augen geführt werden.

Wie P. Scherrer feststellt, ist Strabon in diesem Punkt jedoch ungenau, indem er die beiden topographi-

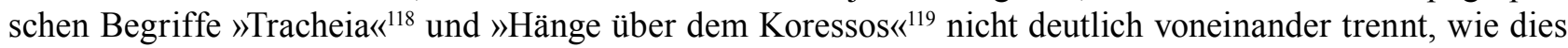
gemäß dem Zitat des Kreophylos eindeutig zu fordern wäre ${ }^{120}$. Dank dieser Beobachtung wird aber sofort klar, dass die von Strabon erwähnte Bergseite ${ }^{121}$, von der man herabgestiegen sei, eindeutig mit Kreophylos' »Hängen über dem Koressos« zu identifizieren ist. Berücksichtigt man nun den bei Strabon immanenten Gegensatz zur ersten Textstelle, wird deutlich, dass auch er den um das »[...] Athenaheiligtum und der Hypelaios [...] « ${ }^{122}$ liegenden Bereich der altionischen Siedlung - die Tracheia - eindeutig von demjenigen auf $\gg[\ldots]$ dem Berghang bei Koressos [...] $\ll^{123}$ unterscheidet. Dieser Umstand ist nun von zentraler Bedeutung. Strabon spricht in keiner Weise von einer großen Umsiedlung, sondern stellt in diesem Zusammenhang lediglich fest, dass man von der Bergseite des Koressos herabgestiegen sei, bzw. dass einzig der auf der Bergseite des Koressos liegende Teil der altionischen Siedlung aufgegeben worden war ${ }^{124}$. Diese Stelle lässt sich daher nur dann verstehen, wenn davon ausgegangen wird, dass man im Zuge der Eroberung durch Kroisos gezwungen war, die Höhensiedlung, d. h. die Akropolis auf dem `Stadionhügek sowie den Bereich an den Hängen über dem Koressos, aufzugeben, während die Tracheia, also der vom Panayırdağ vorspringende Ausläufer nordwestlich des späteren Stadions, weiterhin ein Teil der griechischen Stadt blieb (Abb. 1).

Damit kann man m. E. lediglich in Strabons Überlieferung zur Neugründung der Stadt durch Lysimachos einen Hinweis auf eine Umsiedlung der Bevölkerung und eine damit verbundene Lokalisierung der griechischen Stadt in der Ebene beim Artemision erkennen: »Lysimachos legte die heutige Stadt an; da die Leute nur ungern umsiedelten, wartete er einen Sturzregen ab und half dabei auch selber mit, indem er die Kloaken zusperrte, so dass die Stadt überschwemmt wurde: da siedelten sie mit Freude um. « $^{125}$

$\mathrm{Zu}$ dieser Stelle sei kritisch angemerkt, dass Strabon hier zwar von zwei verschiedenen Stadtgründungen, jedoch wohl von demselben Stadtgebiet spricht. Demnach ist anzunehmen, dass die Stadt zwar neu gegründet wurde, jedoch immer an demselben Ort lag. Der Umstand, weshalb Strabon auch hier keine auf

117 Scherrer 1999, 382. Ähnlich auch Knibbe 1998, 76 f., der ebenfalls darauf hinweist, dass der Athenatempel zur Zeit Strabons noch existiert haben musste. Es ist natürlich nicht auszuschließen, dass das Athenaheiligtum, in welcher Form auch immer, bereits früher bestanden hat. In diesem Sinne Karwiese 1995, 22. - An der Spitze des vom Panayırdağ vorspringenden Ausläufers nordwestlich des späteren Stadions (der Tracheia) und damit außerhalb der hellenistisch-römischen Stadt steht denn auch über einem bis zum Grundwasser herabreichenden Felsspalt ein kleiner Prostylos (Abb. 1, Nr. 78), der von St. Karwiese, Koressos - Ein fast vergessener Stadtteil von Ephesos, in: Pro Arte Antiqua. Festschrift Hedwig Kenner II, SoSchrÖAI 18 (Wien 1985) 215. 219; Karwiese 1995, 54. 117 zu Abb. 15; St. Karwiese, Bauten auf der Akropolis, in: Scherrer (Anm. 36) 190 um 400 v. Chr. und von RE Suppl. XII (1970) 1646 s. v. Ephesos (W. Alzinger) in frühhellenistische Zeit datiert wird. Ähnlich bereits J. Keil, XIII. Vorläufiger Bericht über die Ausgrabungen in Ephesos, ÖJh 24, 1929, Beibl. 48-50. Da der Felsspalt an einer Stelle direkt westlich der Cella zu einem Brunnen erweitert ist und im Tempel zahlreiche weibliche Terrakotta-Gewandfiguren gefunden wurden, stellt sich Scherrer 1999, 383 die berechtigte Frage, ob dieser Bau nicht mit dem von Kreophylos und Strabon erwähnten Athenaheiligtum neben der Quelle Hypelaios zu identifizieren ist. Keil a. O. 49 sprach sich für Apollon aus, Karwiese a. O. 215. 219; Karwiese 1995, 54 schlug Apollo und/oder Leto vor. Alzinger a. O. 1646 lehnte Apollon wegen der weiblichen Terrakotten und der nicht zum Kreophylos-Zitat passenden Lage an der Kapspitze ab. F. Soykal-Alanyali, Überlegungen zu dem Kult von Demeter und Kore, in: Brandt - Gassner - Ladstätter (Anm. 34 ) 319 weist den Tempel hingegen diesen Gottheiten zu. Ebenso lassen nach Groh (Anm. 3) 66 die Bearbeitung der Stirnziegel und figürlichen Terrakotten sowie die Ausgestaltung des Tempels für hellenistische Zeit auf Demeter und Kore schließen. Scherrer - Trinkl 2006, 264 halten schließlich eine Identifikation dieses Tempels mit dem bei Kreophylos und Strabon überlieferten Athenaheiligtum für durchaus wahrscheinlich.

${ }_{118}$ FGrH 417 F 1; Strab. 14, 1, 4.

119 FGrH 417 F 1.

${ }_{120}$ Scherrer 1999, $382 \mathrm{f}$.

121 Strab. 14, 1, 21.

${ }^{122}$ Strab. 14, 1, 21. Übersetzt nach Radt 2005, 23.

123 Strab. 14, 1, 21.

${ }^{124}$ Strab. 14, 1, 21.

125 Strab. 14, 1, 21. Übersetzt nach Radt 2005, 23. 
das Artemision oder den Ayasoluk zu beziehenden topographischen Begriffe verwendet, sondern die Schilderung dieser Ereignisse unmittelbar an die oben zitierte Textstelle und damit auch an die dort erwähnten topographischen Begriffe anschließt, würde sonst unerklärt bleiben. Da Strabon außerdem eindeutig von der heutigen Stadt spricht, mussten die Leute aus dem Gebiet der hellenistisch-römischen Stadt wegziehen und nicht umgekehrt. Strabons Text wird nur dann verständlich, wenn Lysimachos die bereits bestehende Stadt mit einer Mauer umgab ${ }^{126}$, um diese anschließend im Zuge einer Neuplanung um- und neu aufzubauen. Diese Maßnahmen waren mit einer zeitweiligen Umsiedlung der Bevölkerung und der Aufgabe der Nekropole verbunden, welcher die Bewohner am Anfang wohl kritisch gegenüberstanden ${ }^{127}$. Wie auch immer die >Überschwemmungsgeschichte< zu deuten is $\mathrm{t}^{128}$, Lysimachos setzte sich durch und ließ auf dem alten Siedlungsgebiet eine neue Stadt anlegen, wobei auch er sich an die seit der Kroisoszeit bestehende sakrale Achse der Heiligen Straße zu halten hatte und - wie sich zeigt - auch daran hielt. Am Koressos-Hafen beginnend, durchzog die Heilige Straße das Stadtgebiet und als Gräberstraße die Nekropole, um anschließend durch das Umland, eventuell weitere Heiligtümer verbindend, bis zum zentralen Heiligtum, dem Artemision, zu führen. Die hier dargelegten Überlegungen zur Lage der archaisch-klassischen Siedlung von Ephesos bestätigen aber insbesondere eines: »Es zeigt sich jedoch deutlich, dass eine zusammenfassende Beurteilung der wenigen vorhanden Fundstellen im Verein mit den Ergebnissen der Agoragrabung selbst das aus den literarischen Quellen als verlässlich Angesehene zumindest teilweise mit einem Fragezeichen versieht. Die Forschung hat hier also eine wesentliche Aufgabe noch vor sich. $\ll^{129}$

\author{
Mag. Martin Mohr \\ \% Archäologisches Institut der Universität Zürich, Rämistrasse 73, CH-8006 Zürich \\ E-Mail:moro@access.uzh.ch
}

Abbildungsnachweis: Abb. 1: nach DNP III (1997) 1079 f. s. v. Ephesos (P. Scherrer), Bearbeitung Verf.

\footnotetext{
126 Strab. 14, 1, 21 benutzt das Verb $\tau \varepsilon \iota \chi i \zeta \varepsilon ı v$, welches in diesem Zusammenhang wohl besser mit »ummauern« übersetzt wird. Özyiğit (Anm. 3) 95 f. sieht den wichtigsten Hinweis darauf, dass die Stadt ihren Platz nicht verändert hat, in den Stadtmauern der klassischen Zeit. Er vertritt die Meinung, dass die noch heute auf dem Bülbüldağ und dem Panayırdağ aufrecht stehenden Stadtmauern in klassischer Zeit entstanden sind und in hellenistischer Zeit erneuert wurden. Da Hdt. 1, 26 in Zusammenhang

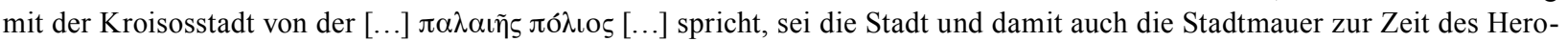
dot erneuert worden. Diese Meinung lässt sich jedoch u. a. aus bautypologischen Gründen nicht halten. Vgl. dazu Marksteiner (Anm. 35) 413-419; Scherrer 2001, 60. Özyiğit (Anm. 3) 95 weist zudem darauf hin, dass »wenn die Stadt wirklich [...] ihren Ort verändert hätte, dann müsste Herodot, der viel früher lebte, dies erwähnt haben.« In diesem Sinne jetzt auch Rubinstein (Anm. 3) 1072: »Herodotos need not imply any more than that the urban centre had expanded considerably since C6 [6 ${ }^{\text {th }}$ century BC.] and that the Artemision thus was no longer situated 7 stades outside the city walls."

${ }^{127}$ Die von Langmann (Anm. 49) 104 Anm. 2 vorgebrachte und in der Folge in der Forschung übernommene Argumentation, dass sich die Bewohner vor allem deswegen weigerten wegzuziehen, weil auf dem neuen Stadtgebiet die alte Nekropole am Panayırdağ lag, bleibt für den oben vorgeschlagenen Verlauf der Ereignisse dieselbe.

128 Allgemein erkennt man in dieser Geschichte weniger eine wahre Begebenheit als ein Problem des hohen Grundwasserspiegels, verbunden mit Überschwemmungen durch die in der Region liegenden Flüsse. In diesem Sinne auch Knibbe 1998, 93, für den sich in dieser Geschichte das Problem des hohen Grundwasserspiegels im Bereich des Artemisions spiegelt. Dasselbe Problem bestand aber gemäß Hueber (Anm. 3) 43 nachweislich auch im Bereich der Tetragonos Agora. Die Textstelle kann demnach auch auf eine in diesem Gebiet liegende Siedlung bezogen werden.

129 Scherrer - Trinkl 2006, 267.
} 